\title{
Observed correlations between aerosol and cloud properties in an Indian Ocean trade cumulus regime
}

\author{
Kristina Pistone $^{1, \mathrm{a}, \mathrm{b}}$, Puppala S. Praveen ${ }^{1, \mathrm{c}}$, Rick M. Thomas ${ }^{1, \mathrm{~d}}$, Veerabhadran Ramanathan ${ }^{1}$, Eric M. Wilcox ${ }^{2}$, and \\ Frida A.-M. Bender ${ }^{3}$ \\ ${ }^{1}$ Scripps Institution of Oceanography, University of California at San Diego, La Jolla, CA, USA \\ ${ }^{2}$ Desert Research Institute, Reno, NV, USA \\ ${ }^{3}$ Department of Meteorology and Bolin Centre for Climate Research, Stockholm University, Stockholm, Sweden \\ anow at: NASA Ames Research Center, Moffett Field, CA, USA \\ ${ }^{b}$ now at: Universities Space Research Association, Columbia, MD, USA \\ ${ }^{c}$ now at: International Centre for Integrated Mountain Development, Kathmandu, Nepal \\ ${ }^{d}$ now at: School of Geography, Earth and Environmental Sciences, University of Birmingham, Birmingham, UK
}

Correspondence to: Kristina Pistone (kristina.pistone@fulbrightmail.org)

Received: 3 August 2015 - Published in Atmos. Chem. Phys. Discuss.: 28 October 2015

Revised: 28 March 2016 - Accepted: 29 March 2016 - Published: 27 April 2016

\begin{abstract}
There are many contributing factors which determine the micro- and macrophysical properties of clouds, including atmospheric vertical structure, dominant meteorological conditions, and aerosol concentration, all of which may be coupled to one another. In the quest to determine aerosol effects on clouds, these potential relationships must be understood. Here we describe several observed correlations between aerosol conditions and cloud and atmospheric properties in the Indian Ocean winter monsoon season.

In the CARDEX (Cloud, Aerosol, Radiative forcing, Dynamics EXperiment) field campaign conducted in February and March 2012 in the northern Indian Ocean, continuous measurements were made of atmospheric precipitable water vapor (PWV) and the liquid water path (LWP) of trade cumulus clouds, concurrent with measurements of water vapor flux, cloud and aerosol vertical profiles, meteorological data, and surface and total-column aerosol from instrumentation at a ground observatory and on small unmanned aircraft. We present observations which indicate a positive correlation between aerosol and cloud LWP only when considering cases with low atmospheric water vapor $\left(\mathrm{PWV}<40 \mathrm{~kg} \mathrm{~m}^{-2}\right.$ ), a criterion which acts to filter the data to control for the natural meteorological variability in the region.

We then use the aircraft and ground-based measurements to explore possible mechanisms behind this observed aerosol-LWP correlation. The increase in cloud liquid wa-
\end{abstract}

ter is found to coincide with a lowering of the cloud base, which is itself attributable to increased boundary layer humidity in polluted conditions. High pollution is found to correlate with both higher temperatures and higher humidity measured throughout the boundary layer. A large-scale analysis, using satellite observations and meteorological reanalysis, corroborates these covariations: high-pollution cases are shown to originate as a highly polluted boundary layer air mass approaching the observatory from a northwesterly direction. The source air mass exhibits both higher temperatures and higher humidity in the polluted cases. While the warmer temperatures may be attributable to aerosol absorption of solar radiation over the subcontinent, the factors responsible for the coincident high humidity are less evident: the high-aerosol conditions are observed to disperse with air mass evolution, along with a weakening of the hightemperature anomaly, while the high-humidity condition is observed to strengthen in magnitude as the polluted air mass moves over the ocean toward the site of the CARDEX observations. Potential causal mechanisms of the observed correlations, including meteorological or aerosol-induced factors, are explored, though future research will be needed for a more complete and quantitative understanding of the aerosol-humidity relationship. 


\section{Introduction}

As nations in southeast Asia have increased bio- and fossil fuel combustion in recent decades, corresponding increases in atmospheric aerosol pollution have been seen over the region (e.g., Ramanathan et al., 2001). The high levels of anthropogenic emissions combine with the seasonal monsoon cycle (Lawrence and Lelieveld, 2010) to cause frequent episodes of heavy air pollution over the northern Indian Ocean, especially in the so-called winter monsoon season (November through March) when the low-level atmospheric flow is northerly to northeasterly, following the temperature gradient from the colder subcontinent to the warmer ocean (Fig. 1).

In addition to their direct effects on the climate (i.e., heating or cooling), aerosols are also known to affect clouds by three primary mechanisms: cloud brightening (e.g., Twomey, 1974; the first indirect effect), precipitation suppression (e.g., Albrecht, 1989; the second indirect effect), and radiative (the so-called semi-direct) effects, which may either enhance or diminish cloud cover based on the cloud type and relative position of the aerosol layer (e.g., Koch and Del Genio, 2010). It is important to note that in addition to the often opposing signs of each of these effects, aerosol-cloud interactions have been shown to be highly dependent on the regime (i.e., the typical meteorological conditions, cloud types, and location) in which they are found (Stevens and Feingold, 2009). That is, the expression of any or multiple aerosol-cloud effects will be dependent on the conditions under which they are expressed and thus may vary from one region to another even when considering superficially similar clouds. In situ observations of all types of clouds are thus critical to understanding the full range of indirect effects influencing the Earth's atmosphere.

The current study builds upon a long history of aerosol studies in the northern Indian Ocean, starting with the Indian Ocean Experiment (INDOEX), a collaborative multiplatform experiment in 1998-1999 involving scientists from several international organizations and led by the Scripps Institution of Oceanography (Ramanathan et al., 2001). In INDOEX, simultaneous multi-platform measurements were made in the Indian Ocean with the goal of observationally constraining direct and indirect effects of aerosols in the region, in particular the atmospheric heating and surface cooling caused by the presence of black carbon (BC) aerosols within the atmospheric column. The intensive field operations allowed scientists to, for the first time, quantify the direct radiative effects of absorbing aerosols originating in southeast Asia and to contrast the highly polluted conditions north of the Intertropical Convergence Zone (ITCZ) with pristine Southern Hemisphere conditions (e.g., Heymsfield and McFarquhar, 2001). INDOEX thus set the stage for later work in the region investigating the effects of absorbing aerosols within the atmospheric column.
The 2006 Maldives Autonomous unmanned aerial vehicle Campaign (MAC) investigated the role of absorbing aerosols in the Indian Ocean, and their effects on clouds, using lightweight unmanned aerial vehicles (UAVs) with miniaturized radiation, aerosol, and cloud instrumentation as payload (Ramanathan et al., 2007; Ramana et al., 2007; Corrigan et al., 2008; Roberts et al., 2008). The UAVs were flown stacked one on top of the other and, with their upward- and downward-looking instrumentation operating simultaneously, directly measured the amount of radiation absorbed within an aerosol layer (Ramanathan et al., 2007). The Cloud, Aerosol, Radiative forcing, Dynamics EXperiment (CARDEX) follows on from these previous studies using UAVs and ground measurements and for the first time incorporates measurements of turbulent kinetic energy and latent heat fluxes for a greater focus on how thermodynamic factors and atmospheric dynamics may influence aerosol effects on clouds.

Between 16 February and 30 March 2012, CARDEX was conducted on Hanimaadhoo Island, Maldives (Fig. 1), led by scientists from the Scripps Institution of Oceanography in San Diego, California, and including collaborators from the Desert Research Institute in Reno, Nevada; Stockholm University in Stockholm, Sweden; the Max Planck Institute for Chemistry in Mainz, Germany; and Argonne National Laboratory in Argonne, Illinois. The Maldives Climate Observatory at Hanimaadhoo $(\mathrm{MCOH})$ has been making continuous measurements of aerosol, radiation, and meteorological parameters on Hanimaadhoo Island since October 2004 (Ramana and Ramanathan, 2006). During the CARDEX campaign, measurements from small aircraft were supplemented with the continuous ground measurements at $\mathrm{MCOH}$, including additional instruments exclusive to the CARDEX period: a mini-micropulse lidar (MPL) to measure cloud base height $\left(z_{\mathrm{cb}}\right)$, boundary layer height $\left(z_{\mathrm{PBL}}\right)$, and the altitude of elevated aerosol plumes; a fast-response water vapor sensor and gust probe (identical to those on the aircraft) to measure turbulent kinetic energy and latent energy fluxes (LEF); and a microwave radiometer (MWR) to measure total-column precipitable water vapor (PWV) and cloud liquid water path (LWP). CARDEX was designed to observe the atmosphere at the end of the so-called dry season (winter monsoon), a time when atmospheric flow over the Maldives is predominantly from the highly polluted Indian subcontinent with little wet removal due to rainfall. As the atmosphere is heavily influenced by anthropogenic pollution during this dry season, the data presented here are valuable for a broader understanding of potential aerosol effects on atmospheric conditions.

Here we present new observations of the dry-season climatology of this trade cumulus regime, including cloud, aerosol, and meteorological properties, as observed during CARDEX. In Sect. 2, we describe characteristics of the full CARDEX data set and two distinct classes of atmospheric properties ("wet" and "dry" regimes) and examine the differing conditions which are responsible for each. Section 3 


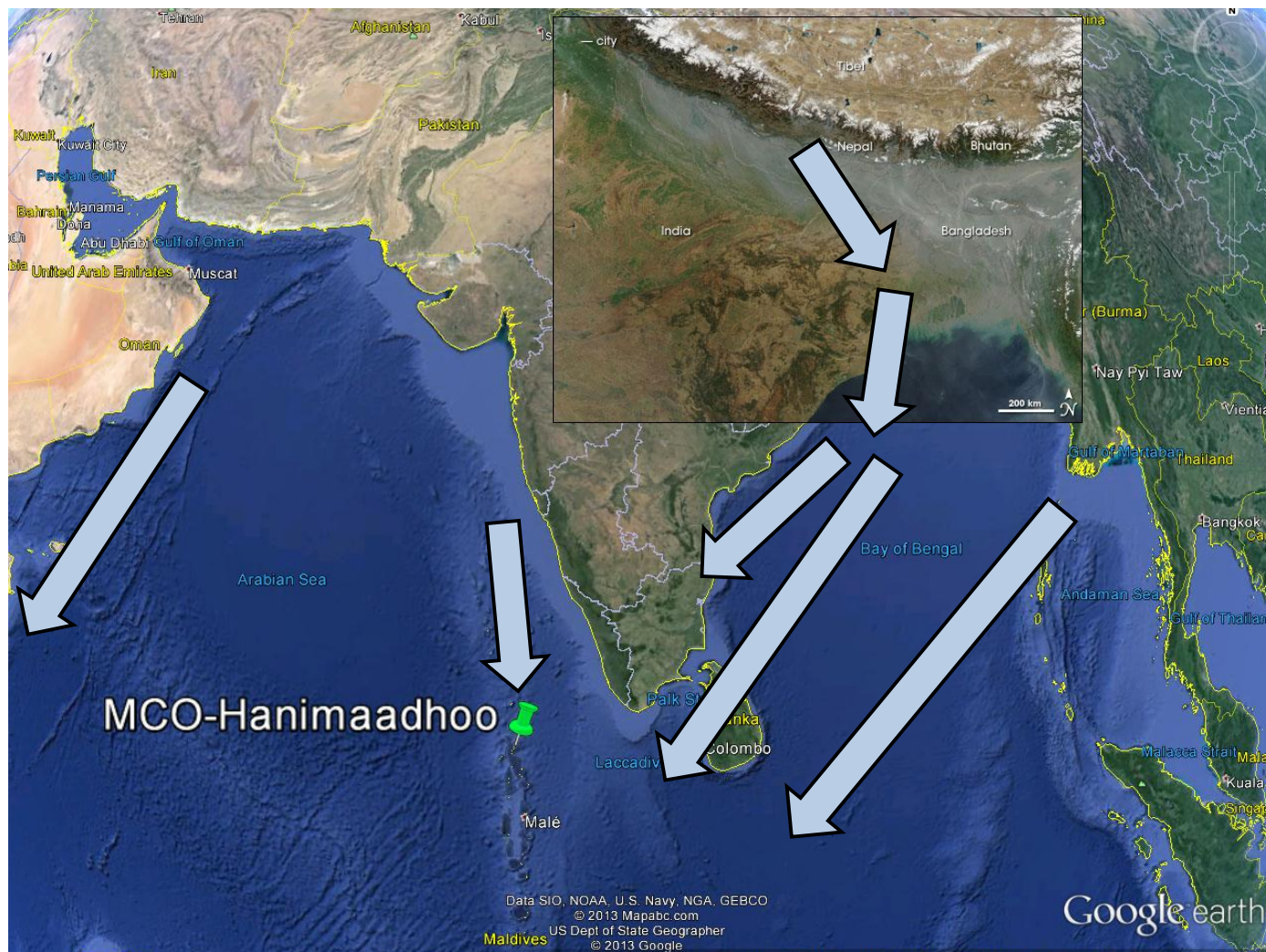

Figure 1. Map of the study location highlighting the Maldives Climate Observatory at Hanimaadhoo (MCOH). The overlay is a NASA MODIS satellite image of the region, showing an aerosol plume coming off the subcontinent. The presence of absorbing aerosols in the plume is evident from its greyish color. Predominant low-level flow during winter months (Lawrence and Lelieveld, 2010) is indicated by the arrows.

then focuses on cases within the dry regime to describe the systematic distinctions observed between low- and highpollution cases as well as observed aerosol-cloud correlations. These pollution case studies allow insight into the mechanisms governing the observed differences in cloud properties. We then offer a brief discussion of some potential causal factors of the observed correlations, including the role of aerosol in modifying atmospheric humidity and the potential implications for the understanding of aerosol effects on clouds.

\section{Methods}

In the following sections, unless otherwise stated, aerosol conditions are determined using the aerosol number concentration measured by the condensation particle counter (CPC) instrument at $\mathrm{MCOH}$ (Fig. 2). Other aerosol metrics used are aerosol optical depth (AOD) measured by the $\mathrm{MCOH}$ AErosol RObotic NETwork (AERONET) sun photometer, satellite-based AOD from the MODerate resolution Imaging Spectroradiometer (MODIS) instruments on board NASA's Terra and Aqua satellites, and BC concentration measured by an airborne or ground-based aethalometer.
The cloud liquid water path (LWP) given here is the average-peak value (the mean of all cloud retrievals within $100 \mathrm{~g} \mathrm{~m}^{-2}$ of the peak cloud value) for each cloud event (Fig. 3). This definition preserves the peak LWP as a characteristic of the cloud (Warner, 1955) while accounting for instrument noise and variability within the cloud. Further discussion of identification and processing of cloud "events" is given in Appendix A1.

Three UAVs were flown during CARDEX. MAC4, MAC5, and MAC6 flew the aerosol and radiation, water vapor flux, and cloud microphysics payloads, respectively. A more detailed description of each payload may be found in Ramanathan et al. (2007), Ramana et al. (2007), Corrigan et al. (2008), Roberts et al. (2008), and Thomas et al. (2012).

A complete description of the permanent $\mathrm{MCOH}$ instrumentation and data used in this paper has been given in Ramana and Ramanathan (2006). Additional information on the CARDEX-specific instrumentation used, including the lidar and the microwave radiometer and the methodology for processing these data, may be found in the Appendix A1. 

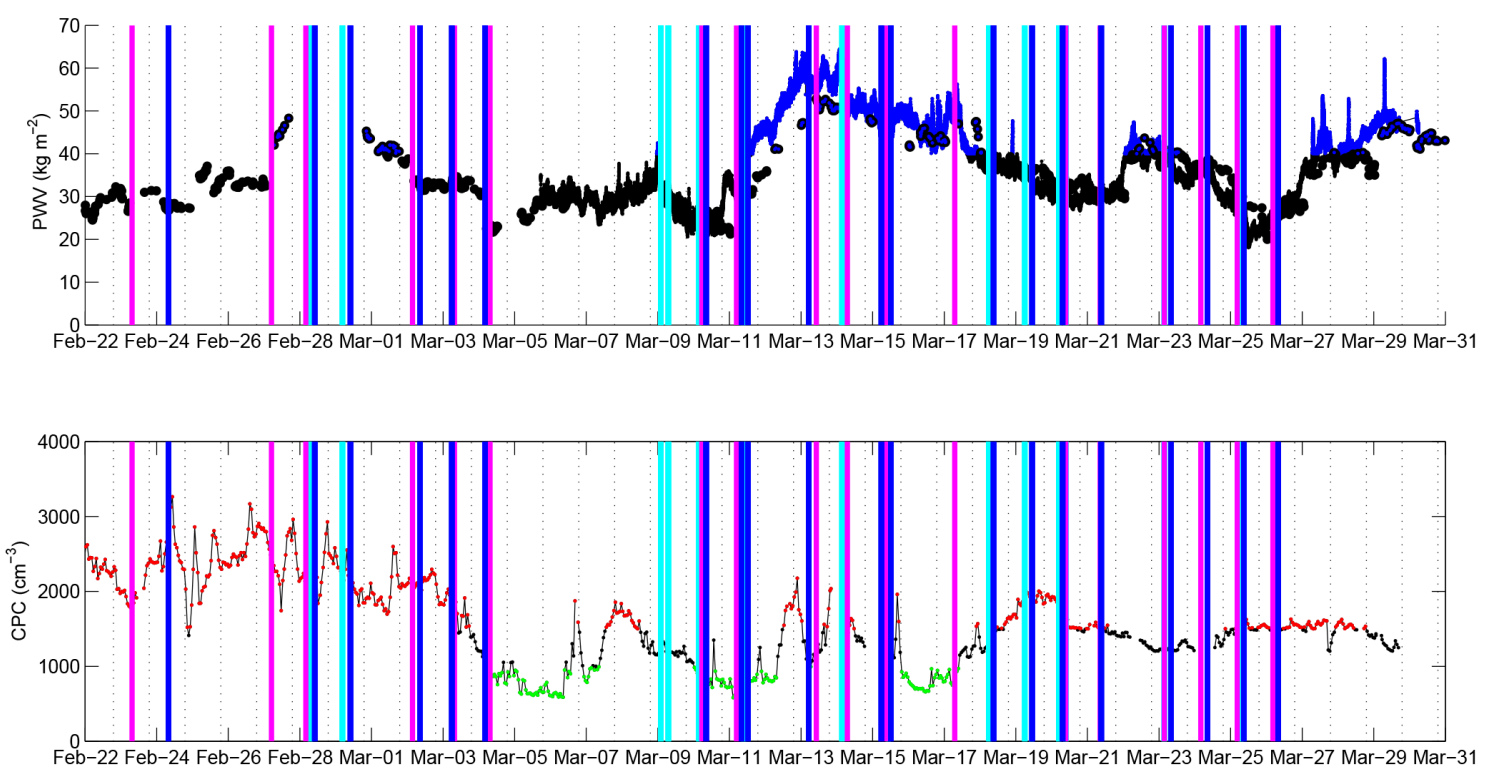

Figure 2. Time series showing the dynamic range of precipitable water vapor (MWR PWV in $\mathrm{kg} \mathrm{m}^{-2}$, upper panel) and surface aerosol concentration (CPC number concentration in $\mathrm{cm}^{-3}$, lower panel) observed during CARDEX. The colors correspond to the regimes described in the text: upper panel shows wet (blue) and dry (black) conditions, and lower panel shows low-pollution (green) and high-pollution (red) conditions. Overlaid vertical lines indicate UAV flight times for the aerosol and radiation (MAC4, magenta), flux (MAC5, blue), and cloud microphysics (MAC6, cyan) planes, showing the wide range of conditions which were sampled.

\section{Atmospheric regime as indicated by total-column water vapor content}

The high variability in total-column atmospheric water vapor observed during CARDEX (between 20 and $60 \mathrm{~kg} \mathrm{~m}^{-2}$, Fig. 2) allows one to categorize the observations as either wet (here defined as total-column PWV $>40 \mathrm{~kg} \mathrm{~m}^{-2}$; blue in Fig. 2) or dry (total-column PWV $<40 \mathrm{~kg} \mathrm{~m}^{-2}$; black in Fig. 2). This distinction is significant in the context of later analysis (Sect. 3); first we describe the notable differences observed between these two regimes.

In this analysis, vapor conditions are identified primarily using the MWR total-column PWV, chosen for its high temporal resolution. Using the good agreement between the MWR and AERONET column PWV, the CARDEX flight days before MWR operations began on 6 March are additionally classified. Daily-averaged PWV conditions for the entire CARDEX period are given in Table 1, and classifications for each UAV flight are given in Table 2.

\subsection{Observed distinctions between dry and wet atmospheric conditions}

Table 3 shows the differences in observed MCOH surface parameters for wet vs. dry conditions at $1 \mathrm{~min}$ resolution. There are some prominent differences between the two populations: on average, dry cases correspond to higher wind speed in both north-south and east-west directions, as well as lower surface pressures; as may be expected, the surface humidity is greater for wet cases, and wet days also exhibit
Table 1. Daily-averaged aerosol and water vapor conditions during CARDEX, indicating days of low $\left(\mathrm{CPC}<1000 \mathrm{~cm}^{-3}\right)$, high $\left(\mathrm{CPC}>1500 \mathrm{~cm}^{-3}\right)$, or intermediate or transitioning pollution conditions $\left(1000<\mathrm{CPC}<1500 \mathrm{~cm}^{-3}\right)$. A "dry" classification indicates that total-column precipitable water vapor was less than $40 \mathrm{~kg} \mathrm{~m}^{-2}$, and "wet" indicates PWV that was greater than $40 \mathrm{~kg} \mathrm{~m}^{-2}$. "Borderline/transition" indicates that the daily average was within $40 \pm 1 \mathrm{~kg} \mathrm{~m}^{-2}$ or that the PWV shifted significantly between dry or wet conditions over the course of the $24 \mathrm{~h}$ period (midnight to midnight, MVT). There were 30 dry and 8 wet days during this period, corresponding to 37 dry- and 13 wet-condition flights. Flights on borderline/transition days may still be classified as wet or dry based on average values measured around the flight time (Table 2). Note that no water vapor data were available on 28 February, though they seem likely to be wet given the conditions of the previous and following days. All flights are visualized in Fig. 2.

\begin{tabular}{lll}
\hline Water vapor & Aerosol & Dates \\
\hline Wet & low pollution & $16-17$ March \\
Wet & middle/transition & $13-15,29$ March \\
Wet & high pollution & $27,(28), 29$ February \\
Dry & low pollution & $4-6,10-11$ March \\
Dry & middle/transition & $7,9,22-24$ March \\
Dry & high pollution & $16-26$ February; \\
& & $2-3,8,19-21$, \\
Borderline/transition & low pollution & 25-27 March \\
Borderline/transition & middle/transition & 18 March \\
Borderline/transition & high pollution & 1,28 March \\
\hline
\end{tabular}


Table 2. CARDEX flights and corresponding surface CPC and total-column PWV conditions for the aerosol and radiation (MAC4), flux (MAC5), and cloud microphysics (MAC6) planes, indicating high $(\mathrm{H})$, medium $(\mathrm{M})$, or low $(\mathrm{L})$ pollution and wet $(\mathrm{W})$ or dry (D) total-column water vapor conditions. Conditions are determined by \pm 2 hourly averages around the flight time (given below in MVT), except for PWV before 5 March, which is determined by average AERONET-retrieved PWV. Note that there was no AERONET retrieval on 28 February and the CPC had a loss of data on 24 March (although the longer time series suggests a middle-level aerosol amount during the missing period).

\begin{tabular}{lll|ll|ll}
\hline Date & \multicolumn{2}{c}{ MAC4 } & \multicolumn{2}{c}{ MAC5 } & \multicolumn{2}{c}{ MAC6 } \\
& $\begin{array}{l}\text { Flight } \\
\text { time }\end{array}$ & & $\begin{array}{l}\text { Flight } \\
\text { time }\end{array}$ & & $\begin{array}{l}\text { Flight } \\
\text { time }\end{array}$ \\
\hline 23 Feb & $12: 30$ & H, D & & & & \\
24 Feb & & & $12: 51$ & H, D & & \\
27 Feb & $10: 00$ & H, W & & & & \\
28 Feb & $09: 00$ & H, NA & $14: 56$ & H, NA & $12: 00$ & H, NA \\
29 Feb & & & $14: 53$ & H, W & $09: 30$ & H, W \\
2 Mar & $08: 30$ & H, D & $13: 29$ & H, D & & \\
3 Mar & $12: 36$ & H, D & $10: 55$ & H, D & & \\
4 Mar & $12: 30$ & L, D & $09: 03$ & L, D & & \\
9 Mar & & & & & $07: 00$ & M, D \\
& & & & & $12: 00$ & M, D \\
10 Mar & $10: 30$ & L, D & $13: 22$ & L, D & $08: 30$ & L, D \\
11 Mar & $09: 45$ & L, D & $13: 09$ & L, D & $14: 30$ & L, D \\
& & & $17: 27$ & L, D & & \\
13 Mar & $15: 15$ & M, W & $10: 14$ & M, W & & \\
14 Mar & $12: 03$ & M, W & & & $08: 30$ & M, W \\
15 Mar & $13: 30$ & M, W & $10: 47$ & M, W & $15: 30$ & M, W \\
& & & $17: 07$ & M, W & & \\
17 Mar & $12: 00$ & M, W & & & & \\
18 Mar & & & $13: 59$ & M, D & $11: 00$ & M, D \\
19 Mar & & & $15: 51$ & H, D & $11: 00$ & H, D \\
& & & & & $15: 30$ & H, D \\
20 Mar & $14: 30$ & H, D & $12: 23$ & H, D & $09: 45$ & H, D \\
& & & & & $14: 30$ & H, D \\
21 Mar & $13: 30$ & M, D & $14: 18$ & M, D & & \\
23 Mar & $08: 30$ & M, D & $12: 58$ & M, D & $08: 30$ & M, W \\
24 Mar & $09: 00$ & (M), D & $13: 32$ & (M), D & & \\
25 Mar & $09: 30$ & H, D & $14: 02$ & H, D & $12: 00$ & H, D \\
26 Mar & $09: 23$ & M, D & $12: 45$ & H, D & & \\
\hline & & & & & & \\
\hline
\end{tabular}

greater variability in cloud LWP. There were no significant differences in observed average aerosol amount (CPC number concentration or AERONET column AOD), cloud base or boundary layer height, or surface fluxes between the two populations when considering the variability of the observations. The frequency distributions of these parameters are visualized in Appendix Figs. A1 and A2.

The vertical profiles from the MAC4 aircraft under wet (dark blue) and dry (cyan, black) conditions are shown in Fig. 4. First, it is notable that in both categories, the UAV profiles indicate large variability in aerosol throughout the atmospheric column (i.e., both boundary layer aerosol and free troposphere aerosol) in terms of CPC number concentration as well as the aethalometer black carbon concentrations measured by the aircraft. Other measured values from
MCOH (Fig. 4, Table 3) show only slight differences between the two populations; in particular, this is true for the average LWP and surface flux values, although the variability in observed LWP is more than a factor of 2 larger for the wet cases. The measured cloud base heights also show greater variability under these wet conditions.

There is on average slightly lower boundary layer humidity for the dry flight days compared with wet days, but the most notable difference between the two populations is in the atmospheric temperature and humidity vertical structure. While the dry days have a very well-defined boundary layer top between roughly 1000 and $1500 \mathrm{~m}$, as indicated by a strong observed temperature inversion and a sharp decrease in relative humidity, the wet days do not. Thus, the most significant distinction in the atmospheric structure of the two populations is in the conditions at the top of and above the boundary layer, namely the lack of temperature inversion and greater atmospheric humidity at higher elevations for the wet cases. This conclusion is additionally supported by the ECMWF reanalysis over MCOH (Appendix Fig. A3a and b).

Note that the atmospheric moisture described here is given as relative humidity $(\mathrm{RH})$, as this metric was directly measured by the aircraft. Although an increase in temperature would produce a decrease in RH for a fixed specific humidity $(q)$, in our cases the measured RH is seen to be consistent with $q$ calculated incorporating changes in temperature.

It is worth noting that during CARDEX, the lidar- and aircraft-measured cloud base heights were generally close in altitude to the inversion (Fig. 4). While many of these clouds likely penetrated at least partway through the top of the temperature inversion, rather than being capped by it, the strength of the observed inversion may help explain the relatively thin clouds in CARDEX as compared with previous works. (A summary of observations from historical trade cumulus studies may be found in Appendix Fig. A4 and Table A1.)

\subsection{Large-scale contrasts between high and low water vapor conditions}

In exploring the mechanisms contributing to this wet versus dry distinction, we compare the air mass back trajectories from the National Oceanic and Atmospheric Administration's HYbrid Single-Particle Lagrangian Integrated Trajectory (NOAA HYSPLIT) model for each case (Fig. 5). This analysis shows that while there is large variability in lowerlevel flow for both wet and dry cases, there are consistent differences in the upper-level flow of each case. On extremely dry days (Fig. 5a), the back trajectories indicate that upperlevel atmospheric flow originates over the Indian subcontinent, traveling in an anticyclonic motion before arriving at $\mathrm{MCOH}$ as northeasterlies. During the 7-day air mass history, the air was continuously descending to the $2-3 \mathrm{~km}$ range. In contrast, for high-PWV conditions (Fig. 5b), upper-level air masses are easterly, approaching from the Bay of Bengal 
Table 3. Average surface values, standard deviations, and 10th and 90th percentile ranges observed for wet vs. dry conditions during CARDEX. Note the highly non-normal distributions of many of these parameters. With the exception of LEF and cloud values, these are calculated from the minute-averaged values for which PWV $<40$ or PWV $>40 \mathrm{~kg} \mathrm{~m}^{-2}$. The LWP and cloud base heights shown are the more meaningful averages over cloud events only; boundary layer height additionally follows this definition to illustrate the position of cloud relative to the boundary layer. Eddy covariance calculations require a 30 min averaging period; additionally, eddy covariance fluxes were unresolvable during nighttime due to the low wind speeds. Thus, the values of LEF below are for 30 min averaged daytime fluxes (06:00-18:00 MVT) only. The corresponding $24 \mathrm{~h}$ values are $74.8 \pm 54.3(6.0-137.3)$ and $67.6 \pm 64.1(3.4-133.7) \mathrm{W} \mathrm{m}^{-2}$ for dry and wet conditions, respectively. Lifting condensation level is calculated from the approximation given in Lawrence (2005).

\begin{tabular}{|c|c|c|c|c|c|c|}
\hline & \multicolumn{3}{|c|}{$\begin{array}{c}\text { Dry conditions } \\
\left(\mathrm{PWV}<40 \mathrm{~kg} \mathrm{~m}^{-2}\right)\end{array}$} & \multicolumn{3}{|c|}{$\begin{array}{c}\text { Wet conditions } \\
\left(\mathrm{PWV}>40 \mathrm{~kg} \mathrm{~m}^{-2}\right)\end{array}$} \\
\hline & Mean & $1 \sigma$ & $10-90$ percentiles & Mean & $1 \sigma$ & $10-90$ percentiles \\
\hline Number of cloud events & \multicolumn{3}{|c|}{267} & \multicolumn{3}{|c|}{363} \\
\hline Cloud LWP $\left(\mathrm{g} \mathrm{m}^{-2}\right)$ & 147.0 & 105.3 & $96.3-187.2$ & 204.2 & 271.4 & $79.9-435.2$ \\
\hline $\operatorname{PWV}\left(\mathrm{kg} \mathrm{m}^{-2}\right)$ & 31.4 & 4.6 & $25.0-37.9$ & 47.8 & 5.5 & $41.0-56.5$ \\
\hline $\mathrm{CPC}\left(\mathrm{cm}^{-3}\right)$ & 1360 & 352 & $789-1797$ & 1218 & 338 & $778-1621$ \\
\hline $\mathrm{AOD}_{500}$ & 0.48 & 0.17 & $0.26-0.66$ & 0.43 & 0.23 & $0.20-0.73$ \\
\hline Wind speed $\left(\mathrm{m} \mathrm{s}^{-1}\right)$ & 2.2 & 1.2 & $0.8-4.0$ & 1.6 & 0.9 & $0.6-2.8$ \\
\hline Surface temperature $\left({ }^{\circ} \mathrm{C}\right)$ & 28.6 & 1.0 & $27.4-30.1$ & 28.8 & 1.1 & $27.5-30.4$ \\
\hline Surface pressure $(\mathrm{hPa})$ & 1008.2 & 1.9 & $1005.6-1010.7$ & 1009.4 & 1.5 & $1007.4-1011.6$ \\
\hline Relative humidity (\%) & 75.6 & 5.3 & $68.5-82.3$ & 77.9 & 4.8 & $71.7-84.2$ \\
\hline Specific humidity $\left(\mathrm{g} \mathrm{kg}^{-1}\right)$ & 18.5 & 1.3 & $16.3-20.1$ & 19.2 & 0.9 & $18.1-20.1$ \\
\hline Boundary layer height (m) & 895 & 193 & $674-1109$ & 841 & 163 & $637-1071$ \\
\hline Cloud base height (m) & 849 & 252 & $583-1208$ & 804 & 371 & $462-1448$ \\
\hline Lifting condensation level (m) & 629 & 137 & $454-812$ & 570 & 127 & $405-731$ \\
\hline Latent energy flux $\left(\mathrm{W} \mathrm{m}^{-2}\right)$ & 79.8 & 56.2 & $11.4-148.9$ & 70.6 & 64.2 & $6.9-135.4$ \\
\hline
\end{tabular}

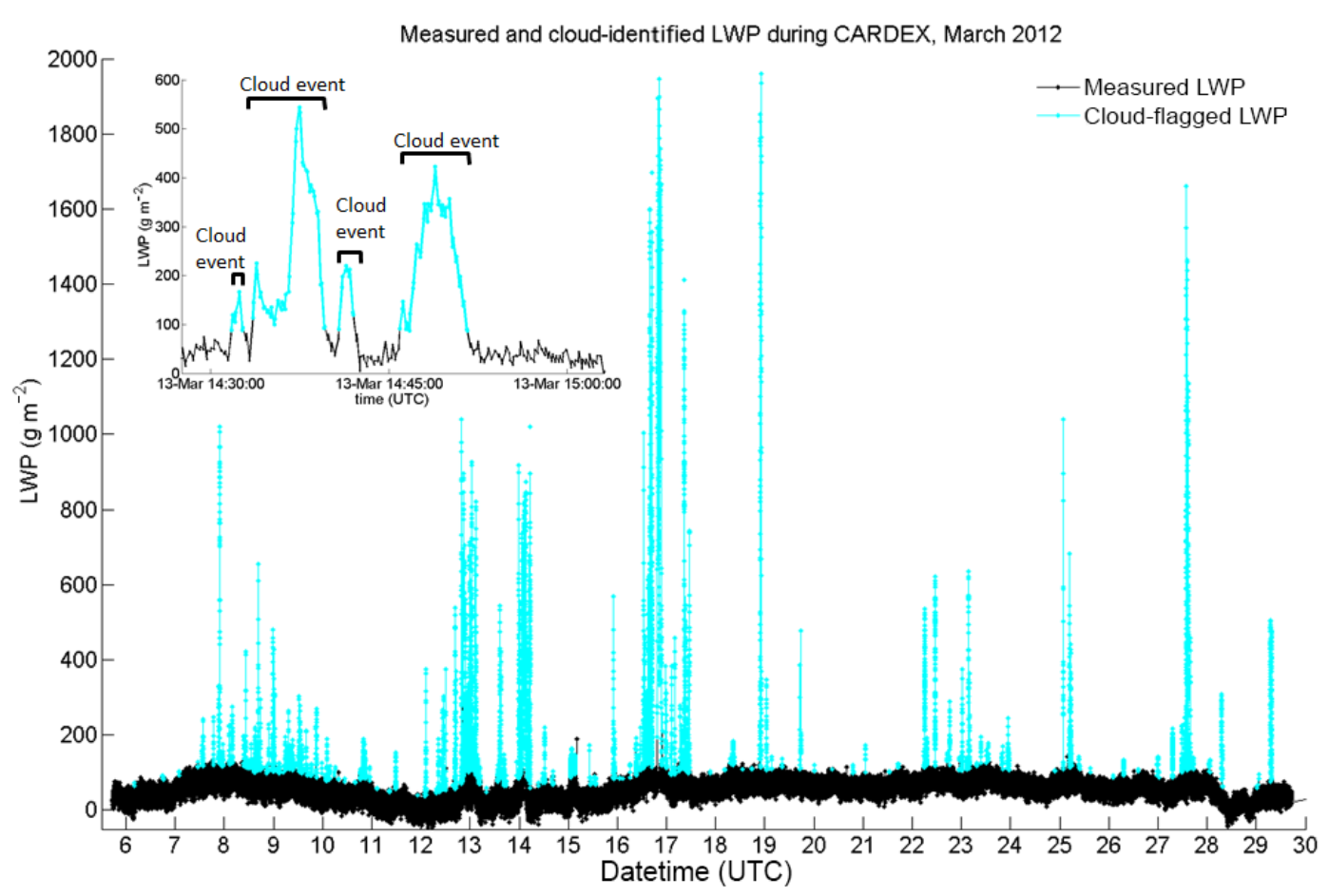

Figure 3. Liquid water path measured by the MWR operated during CARDEX. Cyan points indicate cloud-flagged values, and the inset illustrates an example of cloud events, as described in Appendix Sect. A1. 
Table 4. Average surface values for low, medium, and high pollution for dry conditions (Cases $\mathrm{L}, \mathrm{M}$, and $\mathrm{H}$, respectively). The numbers in parentheses indicate 1 standard deviation of the minute-averaged values for which PWV $<40 \mathrm{~kg} \mathrm{~m}^{-2}$ and $\mathrm{CPC}<$ $1000 \mathrm{~cm}^{-3}$ (low pollution), $1000<\mathrm{CPC}<1500 \mathrm{~cm}^{-3}$ (medium pollution), or CPC $>1500 \mathrm{~cm}^{-3}$ (high pollution). Due to the nonnormal distributions of many of these parameters, the 10th and 90th percentile ranges are additionally shown (second line). LWP and cloud base height are the averages over cloud events only, as is boundary layer height, to illustrate the position of cloud relative to the boundary layer. Lifting condensation level is calculated from the approximation given in Lawrence (2005). Eddy covariance calculations require a $30 \mathrm{~min}$ averaging period; additionally, eddy covariance fluxes were unresolvable during nighttime due to the low wind speeds. Thus, the values of LEF below are for $30 \mathrm{~min}$ averaged daytime fluxes (06:00-18:00 MVT) only. The corresponding $24 \mathrm{~h}$ values are $98.5 \pm 63.4$ (37.4-169.3), $70.4 \pm 51.5$ (5.2-127.8), and $61.0 \pm 42.1(3.3-113.1) \mathrm{W} \mathrm{m}^{-2}$ for Cases $\mathrm{L}, \mathrm{M}$, and $\mathrm{H}$, respectively.

\begin{tabular}{|c|c|c|c|}
\hline & $\begin{array}{r}\text { Case L } \\
\text { low, dry }\end{array}$ & $\begin{array}{r}\text { Case M } \\
\text { med, dry }\end{array}$ & $\begin{array}{r}\text { Case } \mathrm{H} \\
\text { high, dry }\end{array}$ \\
\hline Number of cloud events & 45 & 129 & 89 \\
\hline Cloud LWP $\left(\mathrm{g} \mathrm{m}^{-2}\right)$ & $\begin{array}{l}97.5(19.7) \\
75.0-121.8\end{array}$ & $\begin{array}{r}145(22.3) \\
105.2-163.8\end{array}$ & $\begin{array}{r}175(29.2) \\
109.0-293.6\end{array}$ \\
\hline $\mathrm{PWV}\left(\mathrm{kg} \mathrm{m}^{-2}\right)$ & $\begin{array}{l}29.4(4.2) \\
23.5-34.5\end{array}$ & $\begin{array}{l}31.9(4.9) \\
25.4-38.9\end{array}$ & $\begin{array}{l}31.2(4.2) \\
26.0-37.0\end{array}$ \\
\hline $\mathrm{CPC}\left(\mathrm{cm}^{-3}\right)$ & $\begin{array}{r}767.7(118.9) \\
596-944\end{array}$ & $\begin{array}{r}1319.9(136.9) \\
1138-1487\end{array}$ & $\begin{array}{r}1673.9(169.8) \\
1512-1926\end{array}$ \\
\hline $\mathrm{AOD}_{500}$ & $\begin{array}{r}0.38(0.28) \\
0.14-0.82\end{array}$ & $\begin{array}{r}0.47(0.13) \\
0.26-0.64\end{array}$ & $\begin{array}{r}0.50(0.06) \\
0.45-0.56\end{array}$ \\
\hline Wind speed $\left(\mathrm{ms}^{-1}\right)$ & $\begin{array}{r}2.86(1.20) \\
1.43-4.56\end{array}$ & $\begin{array}{r}2.31(1.31) \\
0.77-4.25\end{array}$ & $\begin{array}{r}1.84(1.01) \\
0.59-3.17\end{array}$ \\
\hline Surface temperature $\left({ }^{\circ} \mathrm{C}\right)$ & $\begin{array}{l}27.97(0.88) \\
26.84-29.02\end{array}$ & $\begin{array}{l}28.64(0.89) \\
27.67-30.07\end{array}$ & $\begin{array}{l}28.80(1.00) \\
27.65-30.26\end{array}$ \\
\hline Surface pressure $(\mathrm{hPa})$ & $\begin{array}{r}1006.5(1.3) \\
1004.9-1008.4\end{array}$ & $\begin{array}{r}1008.0(1.8) \\
1005.4-1010.3\end{array}$ & $\begin{array}{r}1009.0(1.7) \\
1006.8-1011.3\end{array}$ \\
\hline Relative humidity (\%) & $\begin{array}{l}69.7(4.2) \\
63.0-76.7\end{array}$ & $\begin{array}{l}76.4(4.2) \\
70.4-81.2\end{array}$ & $\begin{array}{l}77.4(4.6) \\
71.3-83.5\end{array}$ \\
\hline Specific humidity $\left(\mathrm{g} \mathrm{kg}^{-1}\right)$ & $\begin{array}{l}16.4(1.2) \\
15.1-18.3\end{array}$ & $\begin{array}{l}18.7(0.9) \\
17.6-19.8\end{array}$ & $\begin{array}{l}19.1(0.9) \\
17.9-20.3\end{array}$ \\
\hline Boundary layer height $(\mathrm{m})$ & $\begin{array}{l}1270(173) \\
1009-1460\end{array}$ & $\begin{array}{l}912(161) \\
667-1054\end{array}$ & $\begin{array}{l}784(84) \\
669-863\end{array}$ \\
\hline Cloud base height (m) & $\begin{array}{r}1159(165) \\
882-1290\end{array}$ & $\begin{array}{l}848(268) \\
595-1288\end{array}$ & $\begin{array}{l}820(203) \\
590-1077\end{array}$ \\
\hline Lifting condensation level (m) & $\begin{array}{r}775(139) \\
597-952\end{array}$ & $\begin{array}{r}608(110) \\
481-765\end{array}$ & $\begin{array}{r}583(122) \\
423-746\end{array}$ \\
\hline Latent energy flux $\left(\mathrm{Wm}^{-2}\right)$ & $\begin{array}{r}113.9(66.4) \\
55.7-193.9\end{array}$ & $\begin{array}{r}74.3(54.4) \\
5.5-149.4\end{array}$ & $\begin{array}{l}64.6(40.6) \\
12.7-113.1\end{array}$ \\
\hline
\end{tabular}

and Indonesia, and the $2-3 \mathrm{~km}$ air over $\mathrm{MCOH}$ has ascended from the boundary layer to the free troposphere within 4 days of observation. These results are consistent with the aircraft measurement results (Fig. 4): the primary distinction between wet and dry cases is in the upper-level air mass conditions. In wet cases, this air originates from a more moist (low-level) environment and is transported aloft, while in dry cases it originates from a drier (upper-level) environment and is brought to lower altitude due to strong subsidence in the
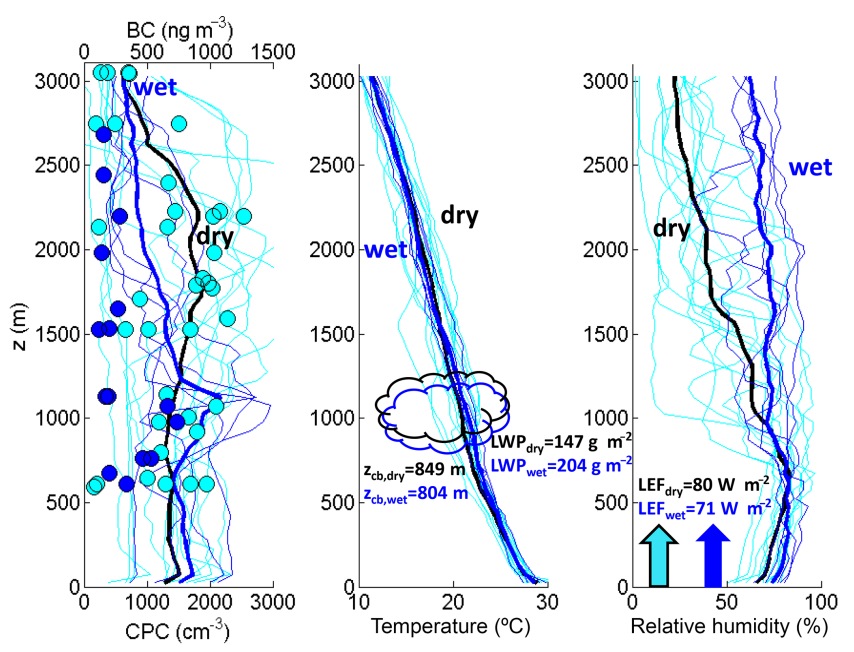

Figure 4. Aerosol, temperature, and relative humidity vertical profiles from the MAC4 aircraft for individual wet (dark blue) and dry (cyan) flights, as indicated by Table 2 . The thin lines indicate individual profiles, and the thick lines indicate the ensemble mean. For visual clarity, the ensemble mean of the dry cases is shown in black, while the individual profiles are in cyan. Black carbon retrievals are shown as discrete circles as they required a period of level flight to obtain an accurate reading. There were 12 dry and 5 wet flights with this aircraft; a description of the flight conditions and times may be found in Table 2. Note that the strong temperature inversion on dry days is most evident in the individual profiles rather than the means, as the latter tends to average out the inversion due to differing boundary layer heights. The average values of LWP, $z_{\mathrm{cb}}$, and LEF are measured at MCOH from the MWR, MPL, and gust probe instrumentation, respectively, and are also shown in Table 3.

atmosphere above the boundary layer. The large-scale meteorological reanalysis from ECMWF is also consistent with this interpretation, suggesting that stronger subsidence and a corresponding increase in low-level divergence are present in the dry cases (Fig. A3c and d). The origin of low-level air again showed no correlation with the wet and dry distinction.

The different characteristics of wet vs. dry cases are thus primarily attributable to differences in the large-scale advection which brings air masses to $\mathrm{MCOH}$, as is evident in the CARDEX observations, the air mass back trajectories, and large-scale reanalysis. This difference in origin corresponds to greater variability in the clouds formed during wet conditions; when considering only the dry cases with a narrower range of variability in LWP, we are able to detect a statistically significant correlation between aerosol and cloud variability. We hypothesize that the greater variability of LWP is a result of unconstrained vertical development of the clouds which form under more humid conditions; as greater humidity tends to increase cloud thickness, greater upper-level humidity may feed cloud development that is decoupled from boundary layer conditions. The variability within the dry cases is the focus of the following sections. 
(a) 10 March 2012

(b) 14 March 2012

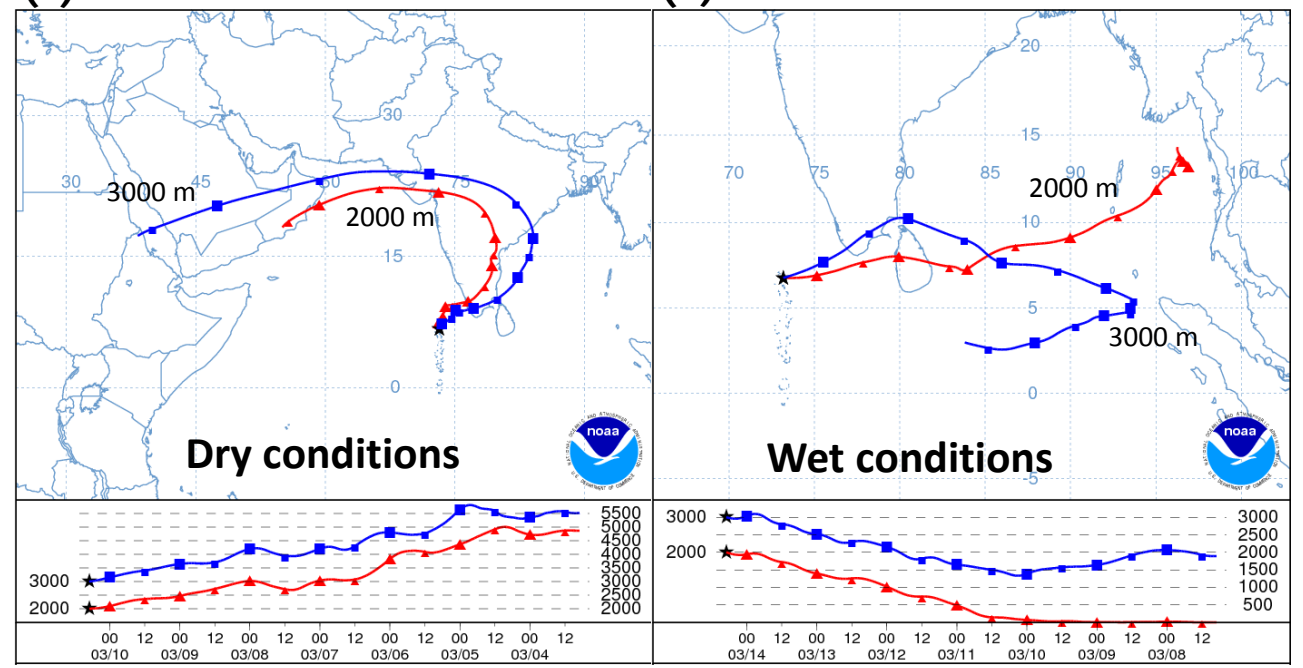

Figure 5. NOAA HYSPLIT 7-day back trajectories arriving at 07:00 UTC (12:00 MVT) for (a) 10 March 2012, a typical dry day, and (b) 14 March 2012, a typical wet day. Visualization from the HYSPLIT-WEB tool (http://ready.arl.noaa.gov/HYSPLIT.php).

\section{Characterization of observed high- vs. low-pollution conditions during CARDEX}

Analysis of the meteorological conditions observed during CARDEX indicated that there was no correlation between cloud liquid water and any measured surface parameter for the CARDEX data set as a whole. High variability is also present in the relationship between the measured cloud liquid water and surface aerosol concentration (Fig. 6a). However, when the data are filtered to take into account meteorology, there is a positive correlation between LWP and aerosol which is significantly greater than 0 (Spearman $\rho=0.48$; Pearson $R=0.42$, both at the $95 \%$ confidence level) for the dry $\left(\mathrm{PWV}<40 \mathrm{~kg} \mathrm{~m}^{-2}\right.$ ) cases only (Fig. 6b). Note that for the Pearson correlation analysis we have taken the logarithmic transform of the LWP as these data exhibit a lognormal rather than normal distribution; the nonparametric Spearman coefficient is insensitive to the logarithmic transform. It is notable that this positive correlation is the opposite of the expected sign of the cloud burnoff effect, despite the presence of significant absorbing aerosol in the region; it is also not indicative of a constant LWP as may be expected in a traditional analysis of the first indirect effect.

In the following section we focus on these dry cases, which correspond to a more well-defined, structured boundary layer as described above. In this analysis, we use all low- or highpollution dry days which had reanalysis and satellite data available (Table 1); observations from the UAVs are necessarily limited to the subset of these days when a UAV was flown (Table 2). "Low pollution" cases are defined as having surface CPC measurements less than $1000 \mathrm{~cm}^{-3}$ (9 flights over 5 days), and "high pollution" cases are defined as having surface CPC greater than $1500 \mathrm{~cm}^{-3}$ (17 flights over 20 days). For simplicity, in the following sections these are referred to as Case L and Case H. The "moderately polluted" cases $\left(1000<\mathrm{CPC}<1500 \mathrm{~cm}^{-3}\right)$ are excluded from the figures in order to bring focus to the high- and low-pollution contrast; however, Table 4 shows that these observations consistently fall between Case L and Case H (e.g., LWP, $z$ PBL, LEF and in many cases are in fact closer to Case $\mathrm{H}$ values (e.g., lifting condensation level, $z_{\mathrm{cb}}$, humidity). This holds true for the UAV vertical profiles ( $T, \mathrm{RH}$, aerosol) as well.

\subsection{In situ measurements of surface and boundary layer characteristics}

The summary of the mean values for each pollution case is illustrated in Fig. 7, with values given in Table 4. Frequency distributions of significant parameters are shown in Fig. 8. As expected, the more polluted dry cases show a higher average cloud LWP; these cases also correspond to lower surface wind speed and lower surface specific and relative humidities, although the total-column PWV did not show a statistically significant difference. Perhaps most strikingly, Case $\mathrm{H}$ shows smaller surface latent heat flux when compared with Case $\mathrm{L}$, indicating that the higher observed atmospheric humidity is not due to increased surface evaporation. While this is in large part due to the lower observed wind speed in Case $\mathrm{H}$, the lower surface fluxes during high-aerosol conditions may partially be a result of surface dimming due to increased atmospheric absorption by black carbon and other absorbing aerosols (Ramanathan and Carmichael, 2008; Stanhill and Cohen, 2001; Wild, 2009).

The UAV flight data offer further valuable insights into the possible mechanisms behind the observed increase in polluted LWP. Figure 9 shows the observed Case L and 

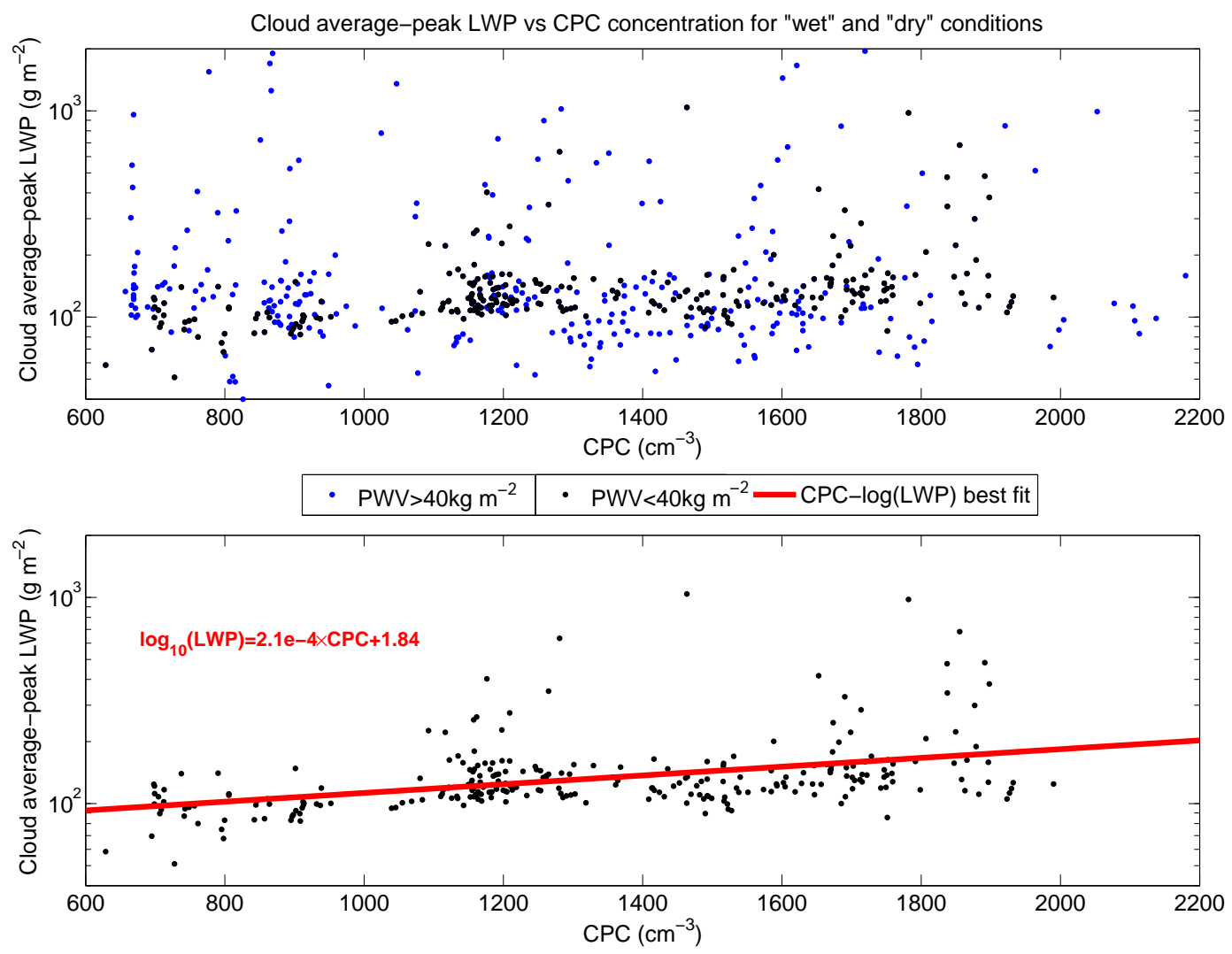

Figure 6. Cloud average-peak liquid water path vs. aerosol concentration, for all clouds (top; wet in blue, dry in black) and only dry condition clouds (bottom). Note the logarithmic scaling on the $y$ axis. The red line indicates the linear best fit between CPC aerosol number concentration and $\log (\mathrm{LWP})$.

Case $\mathrm{H}$ flight profiles from the aerosol-radiation UAV. Note that Case $\mathrm{H}$ is uniformly more polluted (as measured by both the CPC and aethalometer) through the lower atmosphere up to about $2 \mathrm{~km}$, at which point average pollution decreases for both cases. This is true for all cases except for one Case L flight which sampled an elevated aerosol plume. Case $\mathrm{H}$ exhibits warmer temperatures throughout the atmospheric column, with the maximum mean difference between the two cases occurring around the temperature inversion or cloud layer altitude (due to systematic differences in inversion height for Case L vs. H). Note that while Fig. 7 and Table 4 show that the mean temperature measured directly at the surface was not statistically different between the two categories, this is not inconsistent with the aircraft observations, which show a smaller difference between the two cases near the surface compared with higher altitudes. The more polluted cases rather uniformly have higher boundary layer relative humidity and substantially higher free troposphere relative humidity. The brief exception to this is around $800 \mathrm{~m}$, where the humidity of Case $\mathrm{L}$ is greater than that of Case $\mathrm{H}$; this corresponds to differences in the average altitude of the sub-cloud mixed layer between the two cases, which is higher in altitude for Case L. Case $\mathrm{H}$ again has higher $\mathrm{RH}$ above the inversion, which may partly facilitate the correspondingly larger average cloud water content in this case, similar to the hypothesized mechanism behind the variability in cloud liquid water for the wet vs. dry cases as discussed in Sect. 2, though to a lesser degree.

It is clear from these figures that higher-pollution days are correlated with both higher water vapor content and higher temperatures in the entire atmospheric column, particularly around the temperature inversion $(\sim 800-1500 \mathrm{~m})$, which is itself stronger in Case L. The average profiles of equivalent potential temperature in Fig. 9d provide further insight into the differences in thermodynamic structure between each case. The profiles show $\theta_{\mathrm{e}}$ to be constant within the mixed layer, while the saturation equivalent potential temperature $\left(\theta_{\mathrm{e}}^{*}\right.$, dashed line) decreases with height to the lifting condensation level (LCL). The layer of saturation, indicated by values of $\theta_{\mathrm{e}}$ equal to those of $\theta_{\mathrm{e}}^{*}$, is significantly greater in vertical extent for the high-pollution cases (approximately $200 \mathrm{~m}$ thick), whereas the low-pollution profiles barely reach saturation before the temperature inversion. Above this layer is a sharp increase in $\theta_{\mathrm{e}}^{*}$ following the inversion, coincident with a sudden decrease in $\theta_{\mathrm{e}}$ due to the sudden decrease in humidity at the top of the boundary layer. Note that the in- 


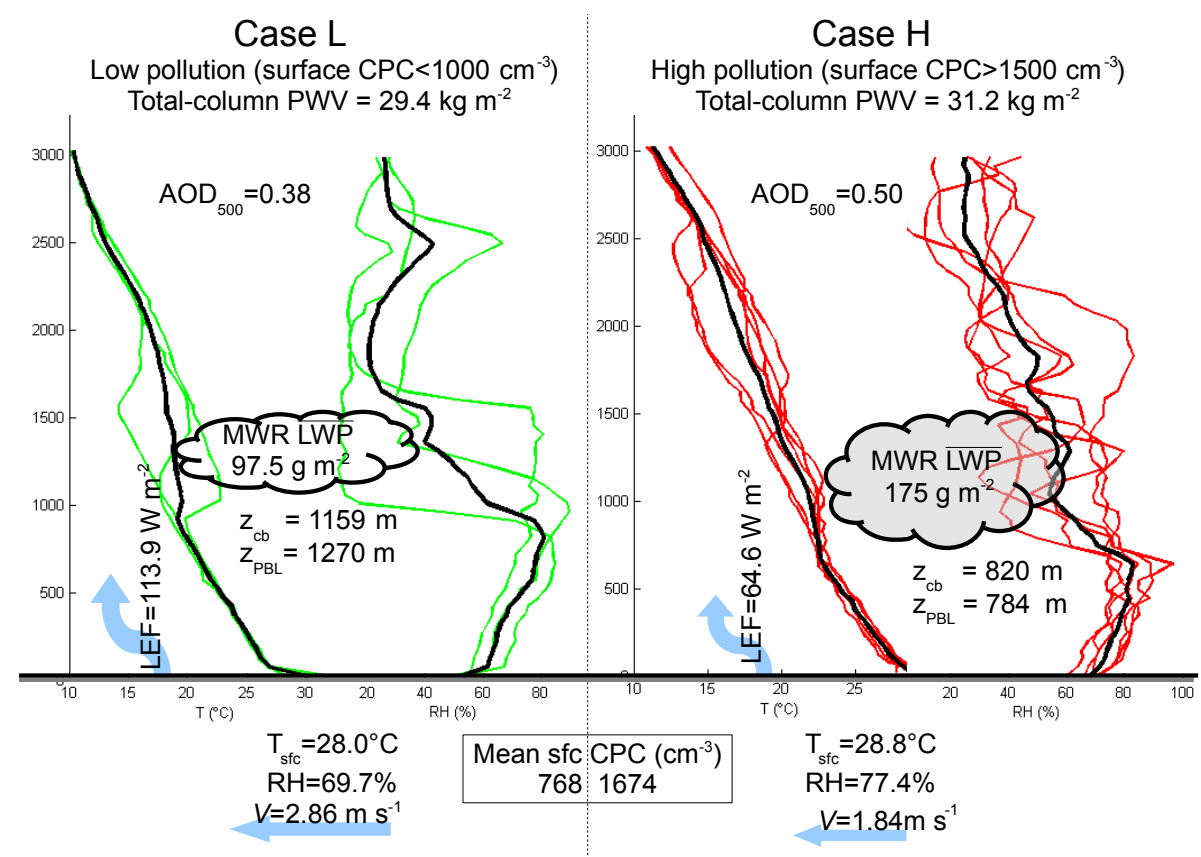

Figure 7. Characteristics of Case L vs. Case H conditions. By definition Case $\mathrm{H}$ has higher surface aerosol concentration; as expected, this is also true for AERONET-measured column AOD. Case H also sees higher humidity (RH), lower surface vapor fluxes (LEF), slightly higher average surface temperatures $\left(T_{\mathrm{sfc}}\right)$, and lower wind speed $(\mathrm{v})$ and, as shown by Fig. 6 , has greater average cloud LWP. The lidar retrievals of cloud base and boundary layer height and the calculated LCL height are systematically lower for more polluted conditions.
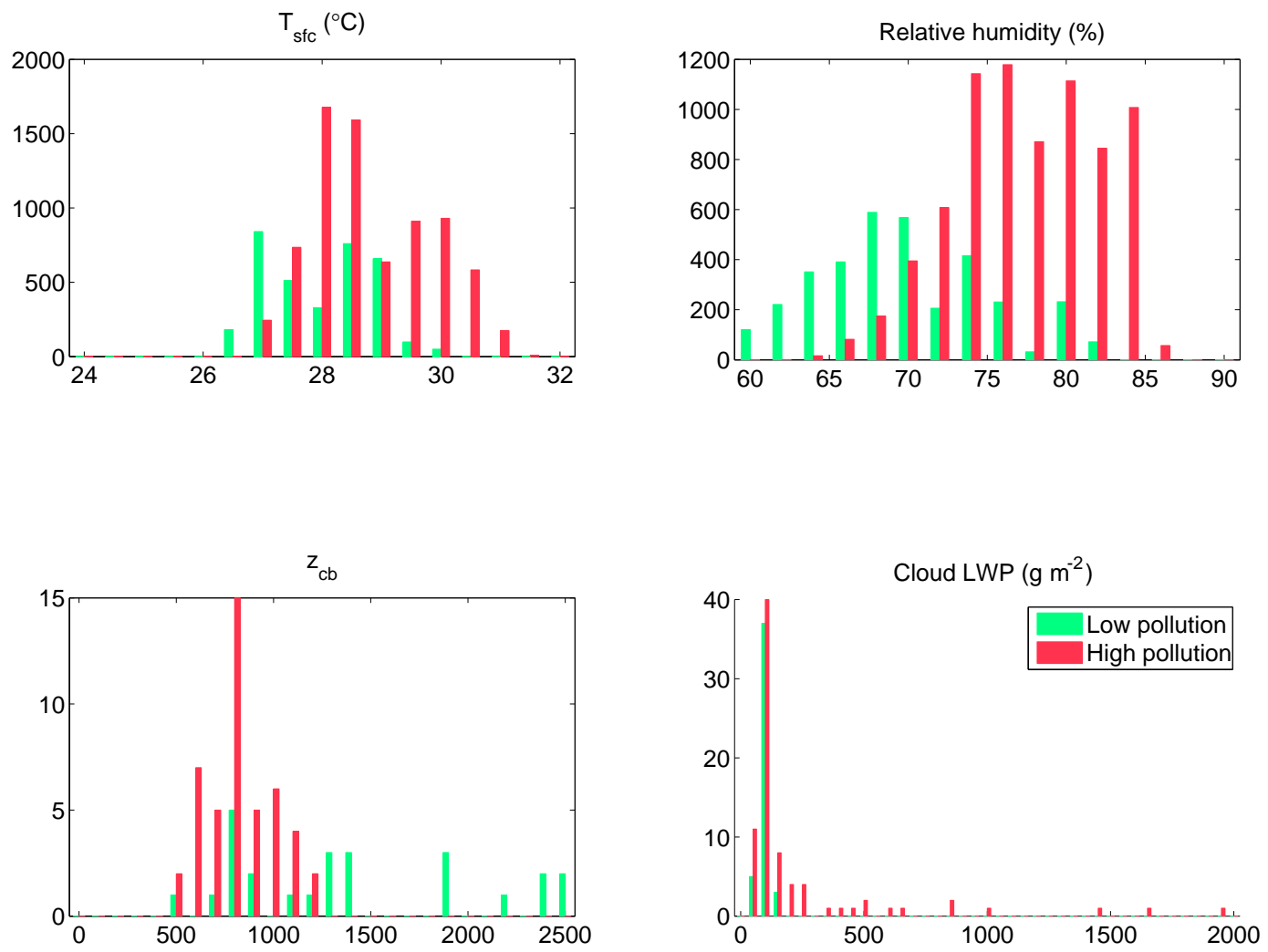

Figure 8. Frequency distributions of surface air temperature and relative humidity (minute data from MCOH), cloud base height (cloudaveraged data from MPL), and cloud liquid water path (cloud-averaged data from MWR) for low- vs. high-pollution cases. 
tersection of $\theta_{\mathrm{e}}$ and $\theta_{\mathrm{e}}^{*}$ is also lower in altitude for Case $\mathrm{H}$, corresponding to the lower $z_{\mathrm{cb}}$. The increase in $\theta_{\mathrm{e}}^{*}$ across the boundary layer top is much greater for Case $\mathrm{L}$ than Case $\mathrm{H}$, indicating that the high-pollution cases are less stably stratified. This, in addition to the greater latent potential energy of these more moist parcels, may result in Case H clouds more frequently achieving convection up through the temperature inversion, resulting in thicker (and thus higher LWP) clouds.

We explore the dependence of LWP on meteorological factors through a calculation of the adiabatic cloud LWC (liquid water content, described in more detail in Appendix Sect. A2) and conclude that an increase in LWP of the magnitude seen in the observations is likely attributable to a physical thickening of the cloud resulting from the lower cloud base; additionally, only the increased atmospheric humidity under polluted conditions, rather than increased temperature, could result in this lower $z_{\mathrm{cb}}$. That cloud bases are lower for the more polluted case is further corroborated by the measured lidar cloud base heights (Fig. 8), which indicated lower average $z_{\mathrm{cb}}$ for highly polluted cases, and by the UAV flight data (Fig. 10), which indicated systematically lower cloud penetrations for high-pollution cases. Although this is not a definitive indication that the cloud bases themselves were lower, as the plane penetrated clouds at a variety of altitudes of undetermined distance above $z_{\mathrm{cb}}$, it is nonetheless consistent with lower cloud bases in Case H. While it was not possible to directly measure cloud top heights during CARDEX, a statistical analysis of cloud tops in the region from the CALIPSO satellite (Wilcox et al., 2014), found higher cloud tops associated with higher pollution levels, which also supports the conclusion of physically thicker polluted clouds.

These multiple data sets paint a consistent picture of the systematic differences between low- and high-pollution cases both at the surface and throughout the atmospheric column. A more polluted atmosphere is observed to be simultaneously warmer, more humid, and more convectively unstable, producing physically thicker, higher-LWP clouds. Further examination of these conditions (Appendix Sect. A2) indicates that only the observed changes in humidity (rather than changes in temperature) would be able to account for differences in cloud height of the magnitude of those observed between low- and high-pollution conditions. We now turn to a larger-scale analysis to further explore the causes of these observed correlations.

\subsection{Large-scale variability between low- and high-pollution cases}

While thus far we have presented aerosol in terms of the surface particle number concentration measured at $\mathrm{MCOH}$, in the following large-scale analysis we use the satelliteretrieved AOD as a metric of pollution level to allow for analysis on a larger scale.

\subsubsection{Regional aerosol patterns}

Figure 11 (top row) shows the difference in mean MODIS AOD over the CARDEX region for the average of Case $\mathrm{H}-\mathrm{L}$ days. That is, $\mathrm{H}-\mathrm{L}$ is taken as the mean of all high-pollution (dry) days minus the mean of all low-pollution (dry) days during the CARDEX period (Table 1). From left to right, the top row panels show the difference between average AOD for 3, 2, 1, and 0 days preceding high-pollution minus lowpollution conditions (as measured at $\mathrm{MCOH}$ ). The separate average Case $\mathrm{L}$ and Case $\mathrm{H}$ values from Fig. 11 with overlaid $1000 \mathrm{hPa}$ wind fields are shown in Appendix Figs. A6, A7, and $\mathrm{A} 8$.

It is evident from this large-scale perspective that the pollution level classifications as determined by the conditions over $\mathrm{MCOH}$ are not necessarily representative of the region as a whole. Indeed, the absolute values of MODIS AOD over the broader CARDEX region for the mean of all Case $L$ days shows that high aerosol concentrations are present elsewhere in the northern Indian Ocean at the same time as low-aerosol conditions dominate at $\mathrm{MCOH}$ (Fig. A6). This is particularly true over the Indian subcontinent, where $\mathrm{H}-\mathrm{L}$ is negative (i.e., the AOD for Case L is significantly higher in magnitude than for Case $\mathrm{H}$ ).

In Case $\mathrm{H}$ and in particular the $\mathrm{H}-\mathrm{L}$ case, it is clear that the air mass of high AOD approaches $\mathrm{MCOH}$ from the north-northwest rather than the east-northeast, corresponding to the $1000 \mathrm{hPa}$ wind field rather than to winds higher in the troposphere and thus indicating that lower-level transport is primarily responsible for the high-pollution conditions at $\mathrm{MCOH}$. Elevated plumes, which approach $\mathrm{MCOH}$ from the northeast, are not the major contributor to aerosol loading on these days. It is also notable that the high aerosol concentration air mass can be seen to dissipate over the 4-day period, indicating a concentrated source and subsequent dispersion of polluted air throughout the region as the plume ages. ECMWF divergence fields (Fig. A9) indicate that there is greater low-level divergence (at the $1000 \mathrm{hPa}$ level) for the low-pollution cases. Although this divergence may act to dilute the polluted air mass, the MODIS AOD shown here suggests that dilution is not the dominant factor distinguishing the two cases. Rather, polluted air is prevented from arriving at $\mathrm{MCOH}$ during the low-pollution cases due to the differences in advection patterns.

\subsubsection{Correlation between large-scale aerosol and temperature}

Figure 11 (middle row) shows the $\mathrm{H}-\mathrm{L}$ mean difference for the ECMWF $1000 \mathrm{hPa}$ temperature field. Similar to the patterns in the MODIS AOD, the high temperatures in Case $\mathrm{H}$ are seen to be concentrated in a region which approaches $\mathrm{MCOH}$ from the north and then dissipates somewhat over the 4 days in question as the polluted air mass is advected southward. The remarkable spatial coincidence of tempera- 

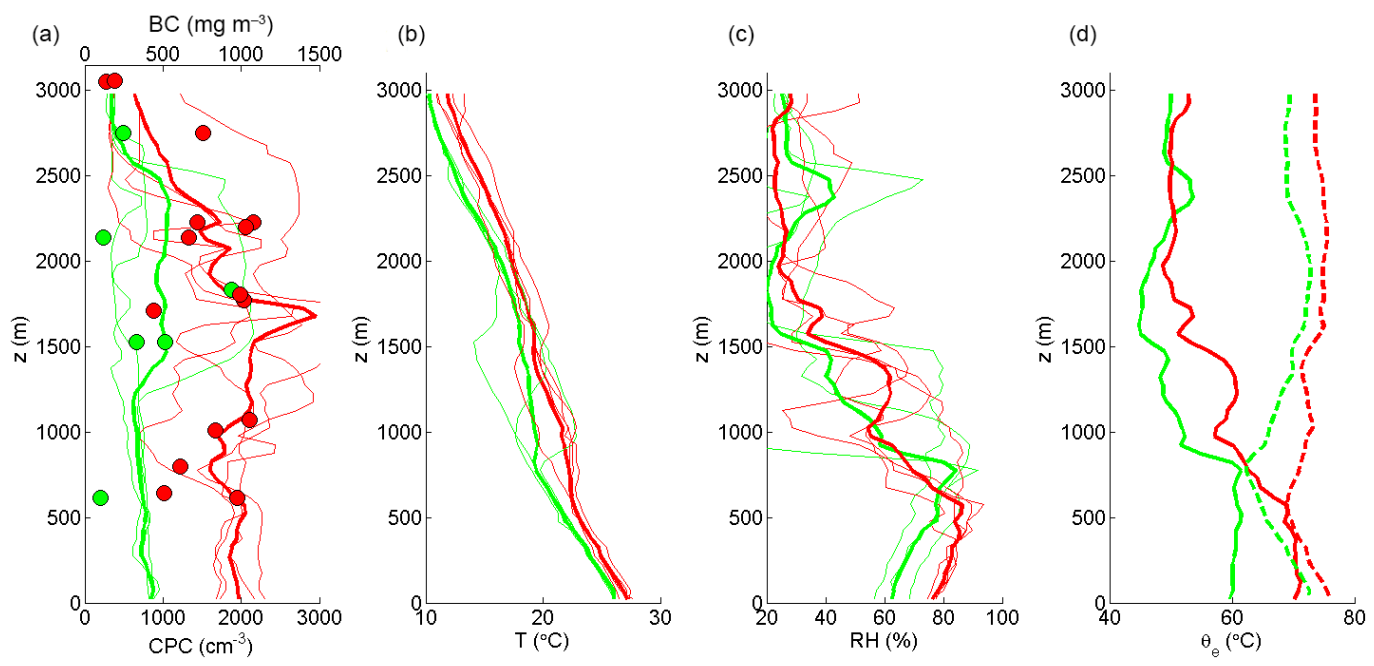

Figure 9. Profiles of (a) aerosol, (b) temperature, (c) relative humidity, and (d) equivalent potential temperature $\theta_{\mathrm{e}}$ from MAC4 for low(Case L; green) and high- (Case H; red) pollution cases. Thin lines indicate the individual flights, and the thick line shows the mean of each case. There were three and five flights with this aircraft, sampling low- and high-pollution dry conditions, respectively. In the left panel, CPC-measured aerosol concentration $\left(\mathrm{cm}^{-3}\right)$ is indicated by lines, while BC retrievals $\left(\mathrm{ng} \mathrm{m}^{-3}\right)$, which required a period of level flight to obtain an accurate measurement, are indicated by colored circles. Case $\mathrm{H}$ has significantly higher aerosol concentration at all altitudes, although this does not universally show an elevated aerosol plume. This case is coincident with warmer atmospheric temperatures and higher humidity at all altitudes. The saturation equivalent potential temperature $\theta_{\mathrm{e}}^{*}$ is shown as dashed lines in (d). Note that due to missing pressure data in two of the MAC4 flights, the calculated variables $\theta_{\mathrm{e}}$ and $\theta_{\mathrm{e}}^{*}$ were determined using two less flights compared with (a)-(c).

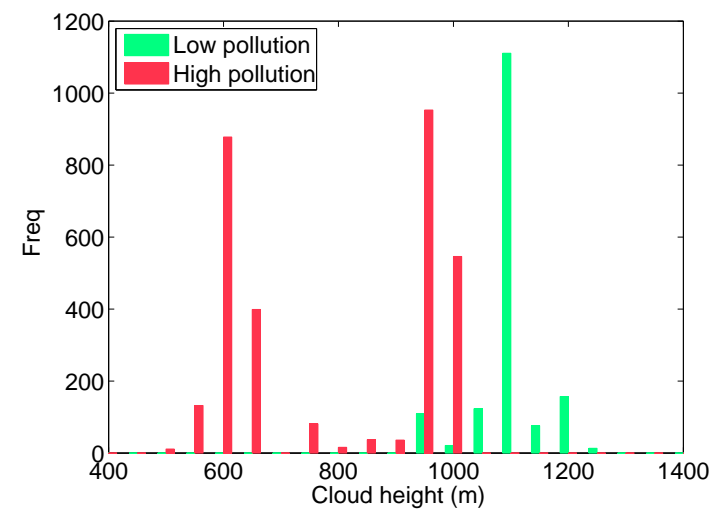

Figure 10. Altitude of cloud retrievals by MAC6 under low- (green) and high- (red) pollution cases, for five high-pollution and two lowpollution flights. Note that this figure shows the height at which the aircraft penetrated the clouds rather than cloud base or top height; however, the observations are consistent with overall lower cloud heights under polluted conditions.

ture with the maximum AOD over all 3 days is strongly suggestive of heating of the air mass due to absorbing aerosol, likely occurring since before the air mass leaves the subcontinent. The rate of aerosol heating was estimated by Ramanathan et al. (2007) to be on the order of $0.5 \mathrm{Kday}^{-1}$ for similar BC concentrations over the same region. The positive temperature anomaly is strongest at the surface; it is similar but weaker in the $900 \mathrm{hPa}$ field and nonexistent at $800 \mathrm{hPa}$.
The analysis of Fig. 11 suggests that regions of high temperature are coincident with higher aerosol. We further explore this relationship with Fig. 12, which shows the correlation between AOD and $T$ over the region. For both pollution cases, Fig. 12 shows a substantial region of statistically significant correlation (95\% level, indicated by hatching) between AOD and $T$. These correlation coefficients (and those in Fig. 13) were determined by calculating the Pearson correlation $R$ between AOD and $T$ for all days in question (i.e., all $\mathrm{H}$ days or all $\mathrm{L}$ days) for each individual $1^{\circ} \times 1^{\circ}$ (latitude, longitude) point. Finally, points were only classified as "significant" if there were no more than $10 \%$ of MODIS retrievals missing. While both Case $\mathrm{L}$ and Case $\mathrm{H}$ are shown for comparison, it should be noted that due to fewer Case $\mathrm{L}$ days being observed (Table 1), the correlations for Case $\mathrm{H}$ (left panel) should be considered more robust. Analysis for all days indicates a similar pattern to Case $\mathrm{H}$, although weaker in magnitude.

The region of high positive and significant correlation for Case $\mathrm{H}$ is present over a broad extent of the Arabian Sea (the low-level source region to $\mathrm{MCOH})$. The correlation weakens in both magnitude and area of significance between Day $\mathrm{H}-2$ and Day $\mathrm{H}$, which further suggests a dispersion of the polluted air mass with time, consistent with the above interpretation of Fig. 11. Case L shows a smaller region of positive correlation concentrated to the north in the Arabian Sea, suggesting that while high pollution and temperature are again coincident, the polluted air mass simply is not advected in the direction of $\mathrm{MCOH}$ in these cases. That is, in 


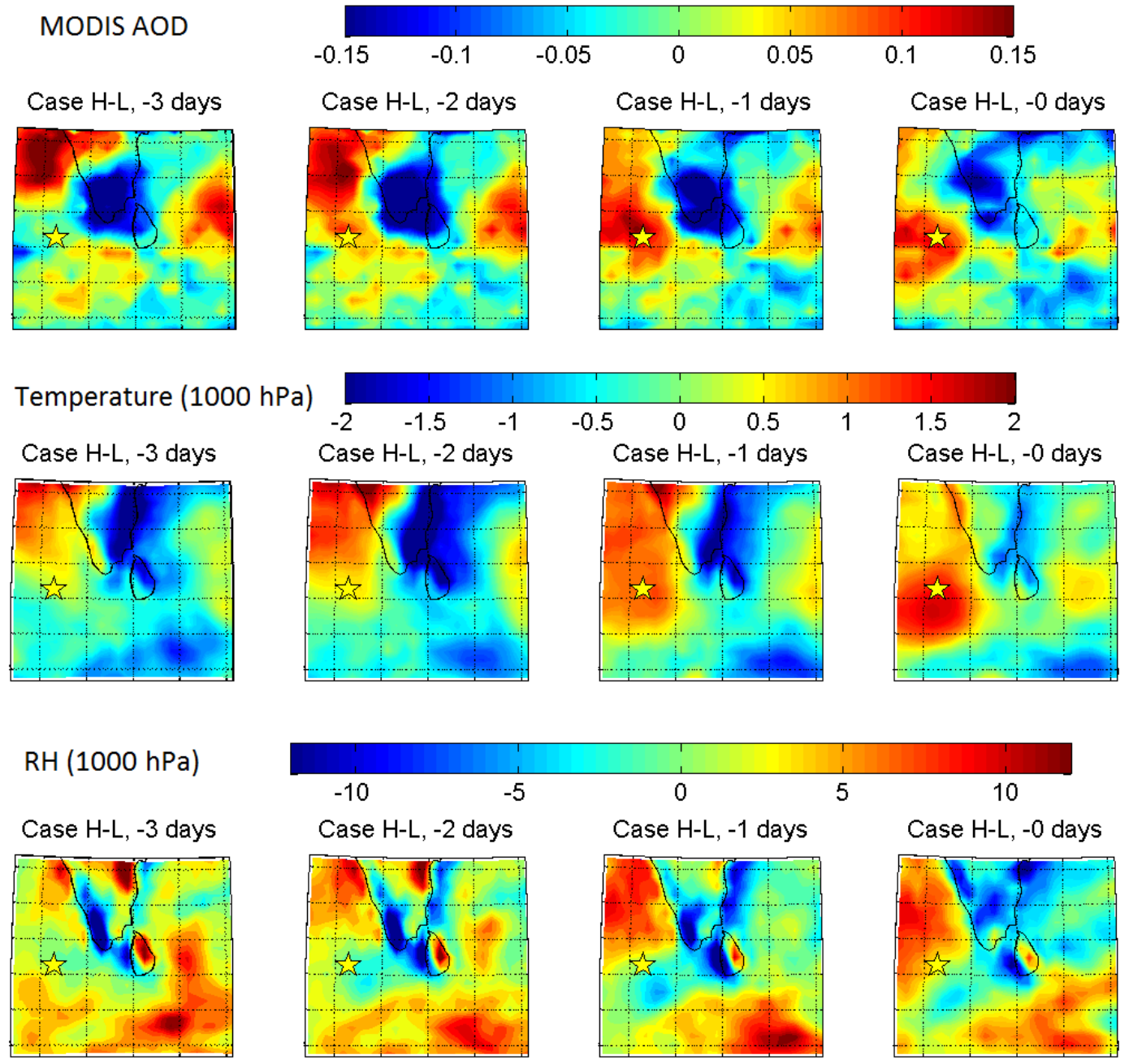

Figure 11. The evolution of the difference in high- minus low-pollution conditions for MODIS AOD (top row) and ECMWF temperature (middle row) and relative humidity (bottom row) at $1000 \mathrm{hPa}$ (approximately $75 \mathrm{~m}$ ) for dry days as identified in Table 1 . The 1-day lag between maximum relative humidity and the maxima in both AOD and temperature is evident in the day-to-day progression. Average Case L and Case $\mathrm{H}$ conditions overlaid with wind fields are shown in Figs. A6-A8.

the so-called low-pollution cases (as defined by conditions at $\mathrm{MCOH}$ ), the high-pollution, high-temperature air mass remains concentrated to the north rather than spreading - and dispersing - southward towards MCOH. Indeed, the difference between regionally averaged AOD for the two cases over the region is only 0.05 , a factor of $2-3$ smaller than the maximum $\mathrm{H}-\mathrm{L}$ difference.

The smaller region of significant negative correlation to the east of the subcontinent (particularly evident in Case $\mathrm{H}$ ) may be explained by low-atmosphere or surface dimming due to an elevated aerosol plume rather than the high boundary layer aerosol responsible for the positive correlation to the northwest; at higher altitudes, for example at $875 \mathrm{hPa}$ ( $z \approx 1250 \mathrm{~m}$ ), the AOD and temperature $T_{875}$ show a strong positive correlation over this region. Elevated aerosol plumes are generally seen to approach $\mathrm{MCOH}$ from this direction, following the upper-level wind field, consistent with the findings of Höpner et al. (2016).

\subsection{Correlations between aerosol, cloud water content, and atmospheric humidity}

The bottom row of Fig. 11 shows the mean $\mathrm{H}-\mathrm{L}$ relative humidity for the larger region surrounding $\mathrm{MCOH}$. Again, there is a notable difference between Case $\mathrm{H}$ and Case $\mathrm{L}$ : the $\mathrm{H}-\mathrm{L}$ field indicates that Case $\mathrm{H}$ corresponds to an air mass of high $\mathrm{RH}$ approaching $\mathrm{MCOH}$ over the 4 days prior to the given event. However, in contrast to the top two rows, the region of highest RH difference is seen to lag the high-AOD and hightemperature region by roughly 1 day and develops rather than disperses with time. That is, the region of higher $\mathrm{RH}$ is seen to be relatively small at -3 days, and subsequently strengthens in magnitude and spatial extent - approximately coinci- 

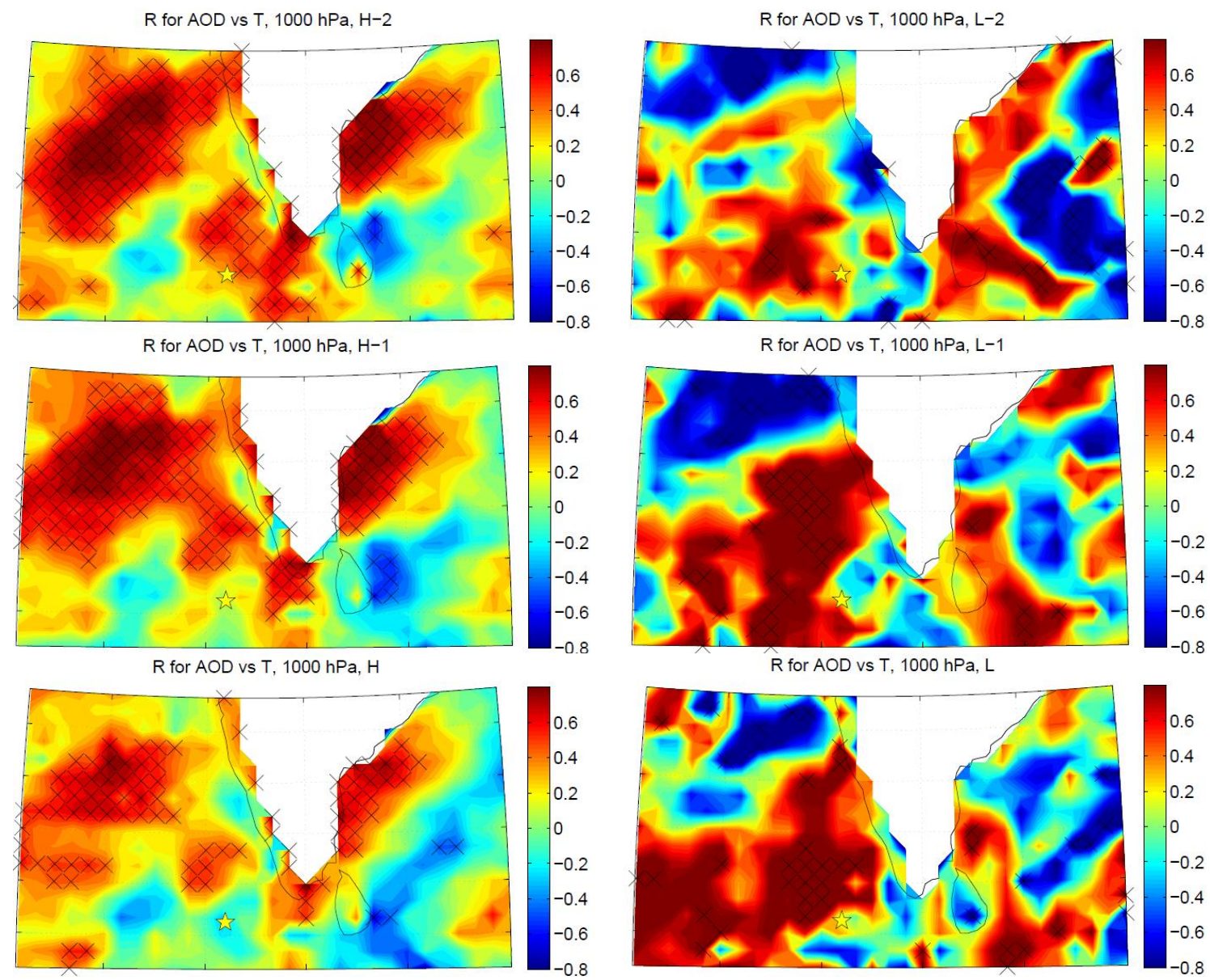

Figure 12. Correlation between AOD and $1000 \mathrm{hPa}$ temperature for days leading up to high- (left) or low-pollution (right) events. The bottom row indicates the average of the days classified as a particular pollution event, while the middle and upper rows indicate the averages of the previous 1 and 2 days, respectively. Hatching indicates a statistical significance at the $95 \%$ level.

dent in location with the high-AOD and high-temperature air mass - in the time leading up to the day in question. This lagged intensification of RH over the 4-day period suggests that some effect within the polluted air mass may be acting to increase its moisture content even as the air mass disperses. This effect is not seen in higher-altitude RH fields.

The correlation between AOD and RH (Fig. 13) exhibits a similar high-low contrast to that observed in the correlations between aerosol and temperature (Fig. 12): Case $\mathrm{H}$ has a weaker correlation over a larger region, whereas Case L is concentrated in a smaller, more highly correlated region. However, this relationship differs significantly from the temperature plots in that instead of dispersing in the 1-2 days prior to Case $\mathrm{H}$, the correlation between $\mathrm{AOD}$ and $\mathrm{RH}$ is seen to strengthen during this period.

While not the only factor, the increased humidity shown in Figs. 6 through 9 and the bottom row of Fig. 11 may to a degree contribute to the observed increase in cloud LWP. As was discussed in Sect. 3.1, this hypothesis is supported by calculations attributing the increase in LWP to the lowering of cloud base heights (Figs. 8 and 10) resulting from increased atmospheric humidity. The atmospheric profiles of equivalent potential temperature (Fig. 9) also indicate that under highly polluted conditions, rising air parcels reach saturation at a lower altitude and the atmosphere exhibits a thicker saturated layer compared with the lowpollution conditions, further supporting the conclusion that the atmosphere is more humid and cloud bases are lower for high-pollution conditions. The large-scale picture shown by Figs. 11 and 13 indicates that, in contrast to the hightemperature condition, this high-humidity condition develops along with the polluted air mass, rather than exiting the continent as simultaneously warm, humid, and polluted.

The question then becomes the following: what may be causing this higher-humidity condition to develop within a polluted air mass? We now explore some potential causal mechanisms by which aerosol may affect atmospheric humidity and, by extension, cloud properties. 

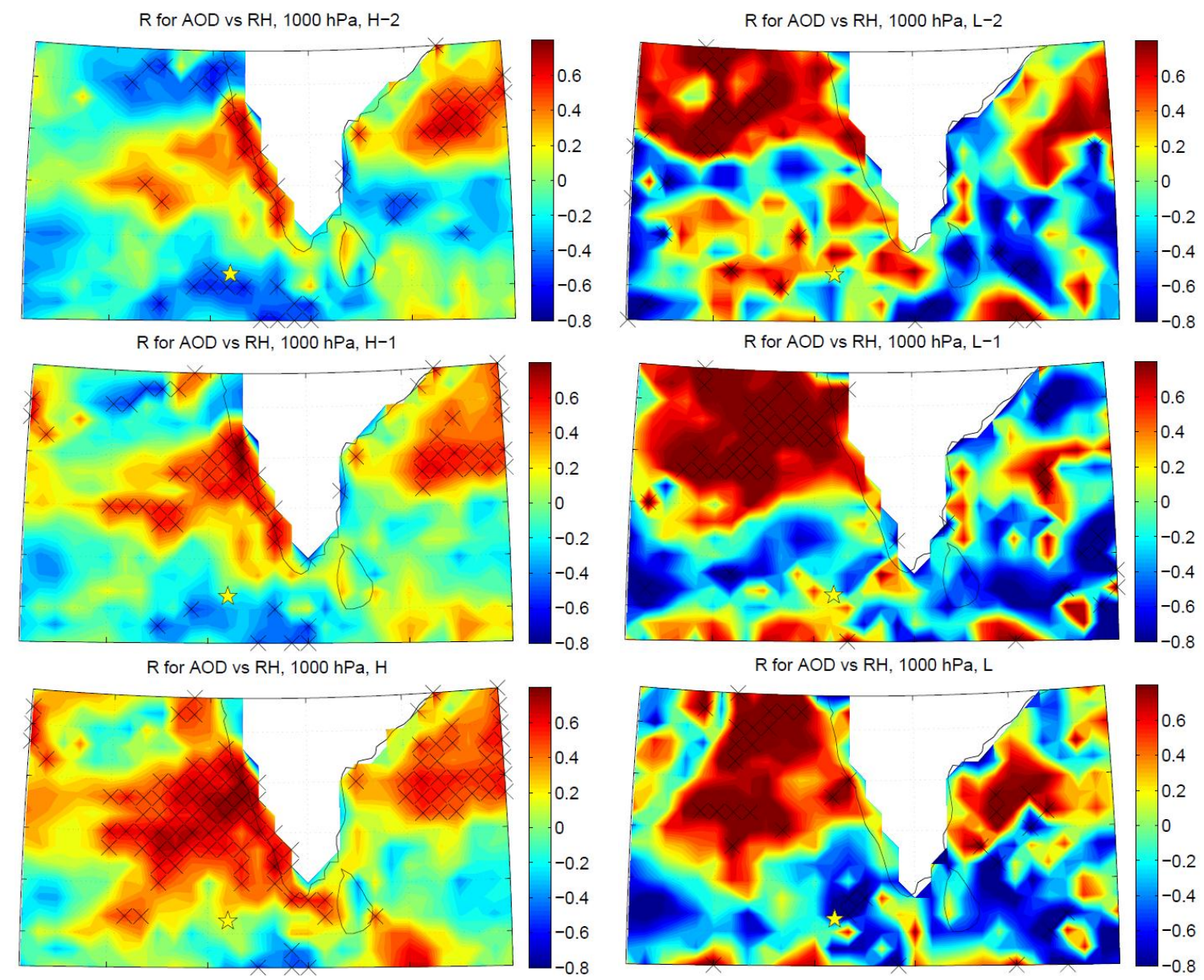

Figure 13. Correlation between MODIS AOD and ECMWF $1000 \mathrm{hPa}$ relative humidity for days leading up to high- (left) or low-pollution (right) events. The bottom row indicates the average of the days classified as a particular pollution event, while the middle and upper rows indicate the average of the previous 1 and 2 days, respectively. Hatching indicates a statistical significance at the $95 \%$ level.

\subsubsection{Discussion of potential humidification mechanisms}

As shown above, there is substantial evidence of a positive correlation between observed aerosol amount and atmospheric humidity. While the present observations are not sufficient to determine the causal mechanism, we are able to briefly explore some possibilities which present interesting avenues for further study. We have previously eliminated sea surface evaporation and decreased cloud formation as the primary causes of the observed higher humidity, due to the flux and LWP measurements already described. We may additionally neglect precipitation in this case, as drizzle was not observed in these clouds even under lowpollution conditions. This leaves large-scale factors (e.g., advection of warm, humid, and polluted air masses), local topof-boundary-layer fluxes, or possible aerosol-induced effects as potential contributing factors to the observed higher relative humidity.
To assess the possible influence of large-scale meteorological conditions on humidity, we examine HYSPLIT back trajectories for any systematic differences in the origin or evolution of the air masses for each case. These show the upperlevel flow approaching from the northeast over the subcontinent, consistent with the results shown in Sect. 2 (Fig. 5b). The near-surface flow originates generally from the north or northwest for both cases; although low-pollution conditions exhibit less extended back trajectories (i.e., lower wind speed above the boundary layer), they come from generally the same direction.

We thus found no clear meteorological distinction (in terms of humidity level or origin) between the two cases which might explain the difference between their boundary layer conditions. While meteorological conditions may be a potential causal factor of the observed correlation between aerosol and cloud properties (e.g., Mauger and Norris, 2007, 2010), the present observations are not sufficient to definitively establish or discard this hypothesis. Further study of the large-scale context is necessary to more fully explore 
the potential meteorological influences on the low- or highpollution distinction and on the aerosol-humidity relationship.

Another possible mechanism to explain the high humidity relates to the temperature-aerosol relationship. While the observed development of the AOD- $T$ relationship (Figs. 11 and 12) is consistent with that of aerosol heating of the air mass (Ramanathan et al., 2007), there are two possible interpretations of how this may relate to the development of highhumidity conditions. First, the humidification of the boundary layer may be a result of the meteorological history of the air mass coincident with aerosol conditions (e.g., Mauger and Norris, 2007); second, aerosol conditions may be directly or indirectly increasing the boundary layer humidity. As shown above, the first interpretation is not supported by the present study, though a more complete analysis is necessary. Regarding the second possibility, aerosol heating may suppress turbulent mixing and stabilize the boundary layer, lowering boundary layer height and inducing higher relative humidity as the polluted plume ages. Alternately, the presence of aerosol heating within the more polluted air mass may be altering the mesoscale circulation to bring more moist air to the region. Again, further study is needed to establish the plausibility of these potential causal mechanisms and to determine whether meteorological or aerosol mechanisms may be primarily responsible for the observed correlations. Regardless of their mechanism, these correlations must be considered in such studies of aerosol-cloud interactions, as secondary changes in atmospheric properties - either directly by aerosol effects or coincident with high-pollution conditions - may alter the effective magnitude of indirect effects. As one example, the first indirect effect relies on the assumption that the amount of liquid water in a cloud is unchanged for clean vs. aerosol-perturbed cases. As cloud albedo is a direct function of cloud liquid water, any coincident changes observed in cloud liquid water content should be considered as this may alter the expected magnitude of the aerosol-induced cloud-albedo effect. These observed correlations require further exploration in future research.

\section{Conclusions}

Here we have presented new results on the characterization of trade cumulus clouds and the dry-season cloud climatology in the northern Indian Ocean using combined ground station observations, vertical atmospheric profiles from UAVs, and large-scale satellite data and meteorological reanalysis. We describe the general characteristics of the atmosphere in the region and illustrate the existence of two separate climatologies based on the water vapor conditions in the atmospheric column, which result in different populations of clouds forming: "dry" conditions result in clouds which tend to be constrained by a well-defined boundary layer topped by an inversion, whereas the clouds forming under "wet" condi- tions exhibit more unconstrained and varied development fed by the availability of more humid upper-layer air. When the data are analyzed according to this climatological separation to filter out the large natural variability of high-vapor conditions, we observe a distinct positive correlation between aerosol concentration and cloud liquid water. Highly polluted conditions (with a high concentration of absorbing aerosol) are found to be systematically warmer and more humid, as seen by the ground, aircraft, and large-scale analyses. From the in situ aircraft and remotely sensed ground observations, we observe a lower boundary layer height under polluted cases, resulting in a lower cloud base which is responsible for the greater cloud liquid water. The observed increase in RH was the only potential factor which could account for the magnitude of the observed difference in cloud LWP which results from this lower cloud base. The large-scale analysis indicates that highly polluted air masses exiting the subcontinent are also warmer initially, while high-humidity conditions develop along with the air mass as it ages.

While the strong correlation between aerosol and temperature is likely attributable to aerosol heating of the air mass (e.g., Ramanathan et al., 2007), with the given observations we are unable to definitively determine a causal mechanism responsible for the observed correlation between aerosol and humidity. Possible mechanisms which may result in these correlations include meteorological or aerosol-driven factors, though at this stage we were not able to attribute the observed differences to differences in large-scale advection patterns. There remains the possibility that aerosol effects may be driving the observed lagged humidification of the boundary layer, either by influencing the mesoscale circulation or stabilizing the boundary layer locally; this is an intriguing avenue for further study.

Understanding the consequences of aerosol-cloud interactions in this region requires an understanding of how variations in atmospheric conditions such as temperature and humidity may impact cloud dynamics and water content. Additionally, future research aiming at understanding aerosolcloud interactions as a whole, and the effects of aerosols influencing atmospheric dynamics specifically, should incorporate both local observations of the instantaneous vertical structure and motion of the atmosphere and large-scale observations to understand the air mass history and the potential influence of meteorology on these effects. 


\section{Appendix A}

\section{A1 Extended methods}

The MWR used during CARDEX was on loan from the Department of Energy's Atmospheric Radiation Measurement (ARM) Climate Research Facility. As described in the instrument's documentation (Morris, 2006), the MWR passively collects microwave radiation at two wavelength bands centered at 23.8 and $31.4 \mathrm{GHz}$, chosen to correspond to predominantly water vapor and liquid water emission, respectively. MWR LWP values were flagged as cloud retrievals if they were more than $35 \mathrm{~g} \mathrm{~m}^{-2}$ above a 1000-point running mean, a value chosen to reflect the instrument noise level and retrieval uncertainty. Two or more consecutive cloud-flagged retrievals are collectively considered a "cloud event" (Fig. 3, inset). An absolute maximum of $130 \mathrm{~g} \mathrm{~m}^{-2}$ was imposed on the running mean to avoid obvious cloud retrievals skewing the background mean. These values were empirically determined to maximize the number of clouds identified, while discounting spurious cloud events that were a product of noise in the instrument. To this end, cloud events are defined as having two or more consecutive cloud-flagged retrievals; all single-retrieval events were excluded from analysis.

The mini-micropulse lidar (MPL) retrievals consisted of vertically resolved backscatter data at $30 \mathrm{~m}$ resolution above $250 \mathrm{~m}$, collected at $0.1 \mathrm{~Hz}$. The MPL was operated daily between 22 February and 30 March for as many hours as was permitted by ambient operating conditions. Completely continuous operation was not possible due to the sensitivity of the instrument to conditions of heat, direct sunlight, and ambient humidity, which required constant operator supervision. The instrument was also switched off around noon particularly as the equinox approached to avoid direct overhead solar glare into the instrument cavity. The MPL was successfully operated for four overnight periods, on 20 and 22-24 March, to fully characterize the diurnal cycle.

Individual UAV flights were classified as wet or dry by taking the average PWV for $\pm 2 \mathrm{~h}$ around the flight time. During CARDEX, the MAC4 aircraft had 12 flights during dry conditions and 5 during wet conditions; the MAC5 aircraft had 15 dry and 4 wet flights; and MAC6 had 10 dry and 4 wet flights. We examine the different aircraft individually due to the differences in flight patterns, with a focus on the MAC4 (aerosol and radiation payload) data in the context of thermodynamic profiling, as this aircraft most frequently profiled the entire lower boundary layer in a systematic (spiral ascending) pattern.

The parameters shown in Fig. 7 and Tables 3 and 4 were calculated based on all minute-averaged surface data except for number of cloud events, cloud LWP, and the cloud base height, which are the averages of the cloud events occurring under the given conditions, and latent energy fluxes, which are the averages of values measured between 06:00 and 18:00 MVT due to limitations in the eddy covariance re-
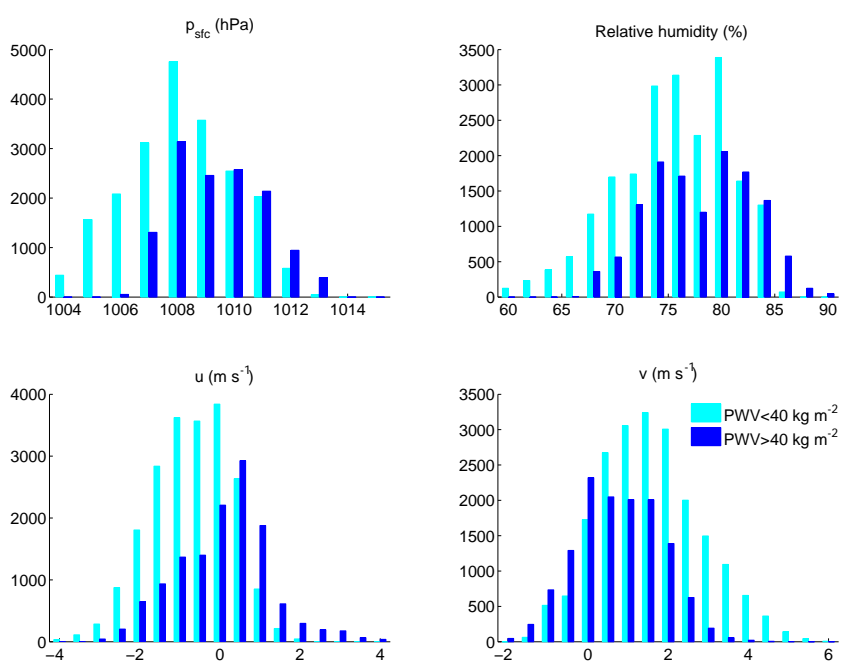

Figure A1. Distributions of minute-resolution $\mathrm{MCOH}$ variables for low $\left(\mathrm{PWV}<40 \mathrm{~kg} \mathrm{~m}^{-2}\right.$, cyan) and high $\left(\mathrm{PWV}>40 \mathrm{~kg} \mathrm{~m}^{-2}\right.$, blue $)$ water vapor conditions. Dry cases on average correspond to a lower surface pressure, lower surface humidity, and faster surface wind speed in both north-south (northerly) and east-west (westerly) directions.

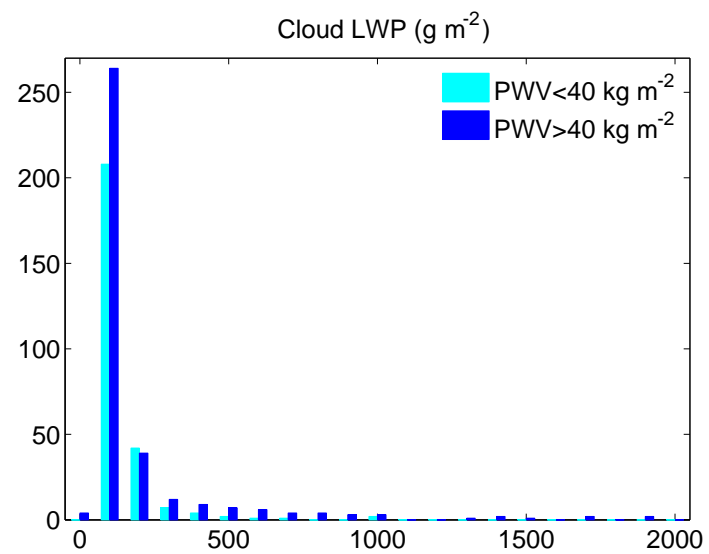

Figure A2. Frequency distribution of cloud LWP for wet (dark blue) and dry (cyan) cases. The clouds in the wet case exhibit more variability in water content than do clouds observed under dry conditions (Table 3), possibly due to a lack of a well-defined boundary layer topped by a temperature inversion, which would act to limit cloud vertical development as in the dry cases.

trievals. The $\mathrm{MCOH}$ values obtained by averaging over just cloudy times are not substantially different from those in Tables 3 and 4 .

The air mass back trajectories are from the NOAA HYSPLIT model, initialized with NCEP-NCAR reanalysis meteorology (available at http://ready.arl.noaa.gov/HYSPLIT_ traj.php; Draxler and Rolph, 2013). The large-scale reanalysis used is the European Center for Medium-range Weather Forecasts (ECMWF) ERA-Interim product (available at http: //apps.ecmwf.int/datasets/; Dee et al., 2011), which provides 

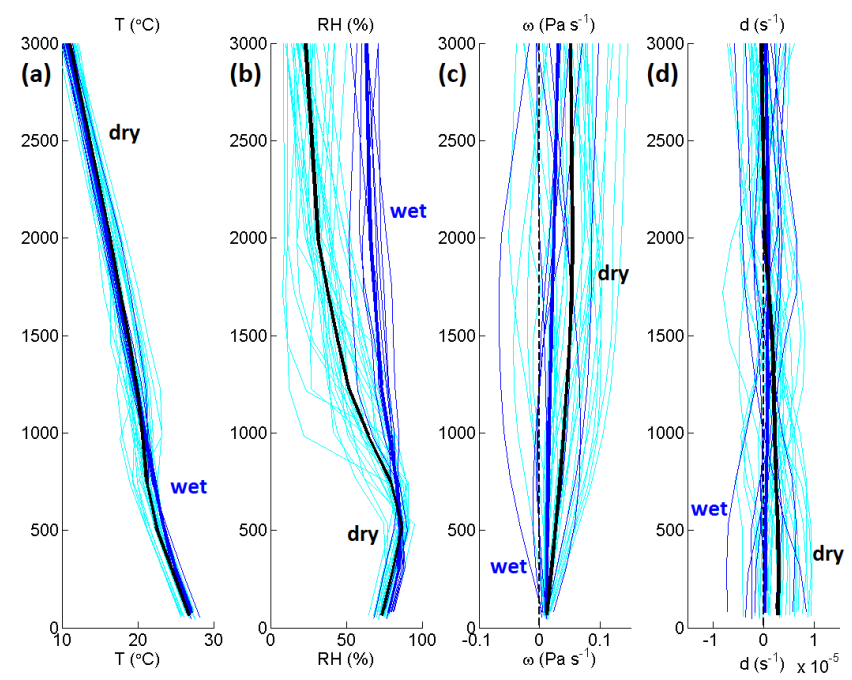

Figure A3. ECMWF temperature, relative humidity, pressure vertical velocity, and divergence over $\mathrm{MCOH}$ for wet (thin blue lines; mean: thick blue lines) vs. dry (thin cyan lines; mean: thick black lines) days during CARDEX. Panels (a, b) exhibit good agreement with the observed vertical profiles measured by the aircraft: as in the flight data, the dry days exhibit a stronger temperature inversion and subsequent drop in humidity, whereas wet cases have consistently higher humidity above the 1000-1500 m inversion. Also consistent with the back trajectory analysis, there is stronger (c) subsidence and corresponding (d) divergence for the dry cases.

large-scale meteorological parameters including vertical velocity, atmospheric convergence, wind fields, temperature, and humidity at 6 -hourly, $1^{\circ} \times 1^{\circ}$ horizontal, and $25 \mathrm{hPa}$ vertical resolution. Unless otherwise noted, the ECMWF time shown is the 06:00 UTC reanalysis (11:00 MVT), chosen to be closest to the overpass times of the satellites used as well as typical UAV flight times. The large-scale AODs shown are the NASA MODIS $1^{\circ} \times 1^{\circ}$ daily gridded Terra and Aqua land and ocean composite AOD at $550 \mathrm{~nm}$, from Collection 5.1 (available at http://modis-atmos.gsfc.nasa.gov/MOD04_ L2/index.html).

\section{A2 Calculations of cloud height and adiabatic cloud liquid water content}

In this section we perform calculations for some idealized hypothetical scenarios to better understand the potential mechanisms behind the observations.

To explore potential causal factors relating to measured cloud liquid water, it is beneficial to explore the relative sensitivity of the LCL (and thus cloud base height) to temperature and relative humidity variability. A simple calculation following Lawrence (2005) indicates that the LCL height $z_{\text {LCL }}$ can be approximated from surface temperature and humidity by the following formula:

$z_{\mathrm{LCL}} \approx\left(20+\frac{T}{5}\right)(100-\mathrm{RH})$.

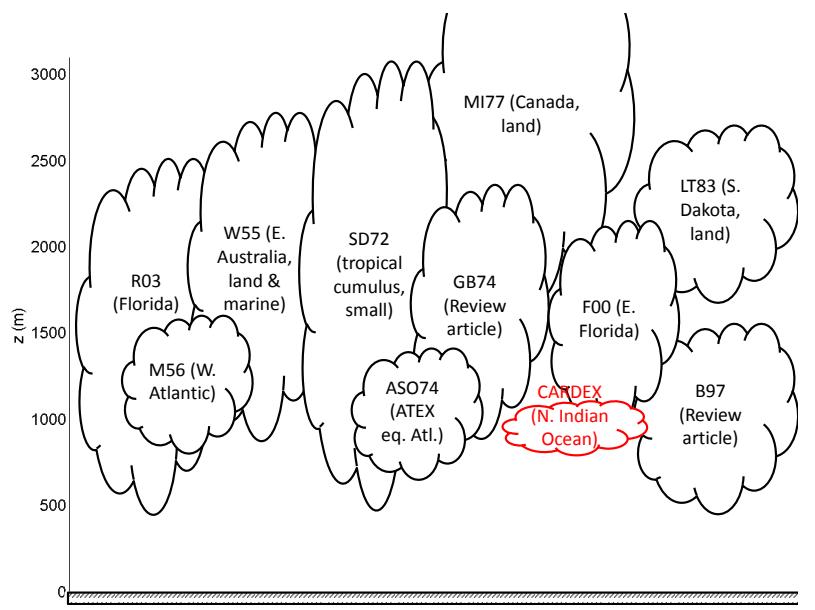

Figure A4. Previous descriptions of small cumulus according to the literature. Note that some clouds, especially those measured over land, are physically larger than the clouds observed in the Indian Ocean during CARDEX. References are those in Table A1.

This calculation indicates that for a constant RH, a change in temperature equal to the extremes of the ranges observed only changes the $z_{\mathrm{LCL}}$ by $24 \mathrm{~m}$, whereas for the extremes in observed RH with a constant $T$, this effect can change the $z_{\mathrm{LCL}}$ by over $500 \mathrm{~m}$. Using the mean values of Case $\mathrm{L}$ and Case $\mathrm{H}\left(T_{\mathrm{L}}=28^{\circ} \mathrm{C}, \mathrm{RH}_{\mathrm{L}}=70 \%\right.$ and $T_{\mathrm{H}}=29^{\circ} \mathrm{C}, \mathrm{RH}_{\mathrm{H}}=$ $77 \%$ ), changes solely in $\mathrm{RH}$ between $\mathrm{L}$ and $\mathrm{H}$ are found to lower the lifting condensation level by $200 \mathrm{~m}$, consistent with observed differences in $z_{\mathrm{LCL}}$. This compares with a change of approximately $5 \mathrm{~m}$ resulting from a temperature change only. Thus, the LCL is primarily determined by changes in $\mathrm{RH}$. Note that the calculated $z_{\mathrm{LCL}}$ is $200-300 \mathrm{~m}$ lower than the $z_{\mathrm{cb}}$ indicated by the MPL; as surface air parcels ascend towards the LCL, they will mix with drier, cooler surrounding air, a factor which will raise cloud base height but is not accounted for in this idealized calculation.

Using the above result, we take changing the cloud base height to be a proxy for the effect of changing atmospheric RH.

We explore the magnitude of each effect (changing temperature vs. changing relative humidity) on the resulting cloud by calculating adiabatic cloud LWP for clouds of varying thicknesses and heights using values observed in CARDEX (Fig. A5; Table A2). While trade cumulus in particular have been observed to be significantly (60-90\%) subadiabatic (Curry and Webster, 1999; Warner, 1955), with subadiabaticity increasing with cloud thickness, a calculation of the adiabatic liquid water provides a useful metric to diagnose the relative magnitude of a given change on the cloud liquid water content.

Table A2 and Fig. A5 indicate the magnitude of each effect (i.e., independently varying the relative humidity and temperature observed in Cases $\mathrm{H}$ and $\mathrm{L}$ ) on the cloud liquid water content. Temperature is taken to be the measured mean val- 
Table A1. Trade cumulus cloud properties as measured in previous studies.

\begin{tabular}{|c|c|c|c|c|c|c|}
\hline Study & $\begin{array}{c}\text { Cloud } \\
\text { base }\end{array}$ & $\begin{array}{r}\text { Cloud } \\
\text { top }\end{array}$ & $\begin{array}{l}\text { Cloud } \\
\text { width }\end{array}$ & $\begin{array}{r}\text { Cloud } \\
\text { lifetime }\end{array}$ & $\begin{array}{l}\text { Updraft } \\
\text { velocity }\end{array}$ & LWC \\
\hline Malkus (1956) ${ }^{\mathrm{a}}(\mathrm{M} 56)$ & $705 \mathrm{~m}$ & $1.2-1.8 \mathrm{~km}$ & & & $3-6 \mathrm{~cm} \mathrm{~s}^{-1}$ & \\
\hline Warner $(1955)^{\mathrm{b}}(\mathrm{W} 55)$ & $0.8-1.4 \mathrm{~km}$ & $2.6-3.3 \mathrm{~km}$ & $>600 \mathrm{~m}$ & $>30 \mathrm{~min}$ & & $0.4-1.4 \mathrm{~g} \mathrm{~m}^{-3}$ \\
\hline Simpson and Dennis $(1972)^{\mathrm{c}}$ (SD72) & $500 \mathrm{~m}$ & $3 \mathrm{~km}$ & $500 \mathrm{~m}$ & $5-10 \min$ & $2-3 \mathrm{~ms}^{-1}$ & $1-3 \mathrm{~g} \mathrm{~m}^{-3}$ \\
\hline Augstein et al. (1974) ${ }^{\mathrm{d}}$ (ASO74) & $600 \mathrm{~m}$ & $1.3-2 \mathrm{~km}$ & & & & \\
\hline MacPherson and Isaac (1977) ${ }^{\mathrm{f}}$ (MI77) & $1700 \mathrm{~m}$ & $4400 \mathrm{~m}$ & $3.2 \mathrm{~km}$ & & & \\
\hline LaMontagne and Telford (1983) ${ }^{\mathrm{g}}$ (LT83) & $1700 \mathrm{~m}$ & $2650 \mathrm{~m}$ & & & & \\
\hline Betts $(1997)^{\mathrm{h}}($ B97) & $950 \mathrm{hPa}$ & $800 \mathrm{hPa}$ & & & & \\
\hline French et al. (2000) (F00) & $\sim 900 \mathrm{~m}$ & $2-2.9 \mathrm{~km}$ & $1 \mathrm{~km}$ & $\sim 30 \mathrm{~min}$ & $4 \mathrm{~ms}^{-1}(5-7 \mathrm{max})$ & $0.5-2 \mathrm{~g} \mathrm{~m}^{-3}$ \\
\hline Rodts et al. (2003) (R03) & $500 \mathrm{~m}$ & $2500 \mathrm{~m}$ & $10 \mathrm{~m}-3 \mathrm{~km}$ & & & \\
\hline
\end{tabular}

${ }^{\mathrm{a}}$ Western Atlantic data, 1946 and 1953. ${ }^{\mathrm{b}}$ Measured vertically resolved LWC within a cloud. Column LWP may be derived through vertical integration, yielding values of 800-1400 $\mathrm{g} \mathrm{m}^{-2} .{ }^{\mathrm{c}}$ Clouds are subadiabatic due to entrainment of outside air. ${ }^{\mathrm{d}}$ ATEX (1969) experiment in the equatorial Atlantic. ${ }^{\mathrm{e}}$ Following observations made by Malkus (1956) and others. Clouds are capped by an inversion. ${ }^{\mathrm{f}}$ Terrestrial (Canadian) cumulus, including some towering cu. Peak $w$ was seen in the downdrafts rather than updrafts. ${ }^{\mathrm{g}}$ Terrestrial (South Dakota) cumulus, August 1978. Observations are from a site $1200 \mathrm{~m}$ a.s.l. Altitudes as reported are relative to mean sea level. ${ }^{\mathrm{h}}$ For comparison, the heights in hPa correspond to roughly 500 and $1500 \mathrm{~m}$.
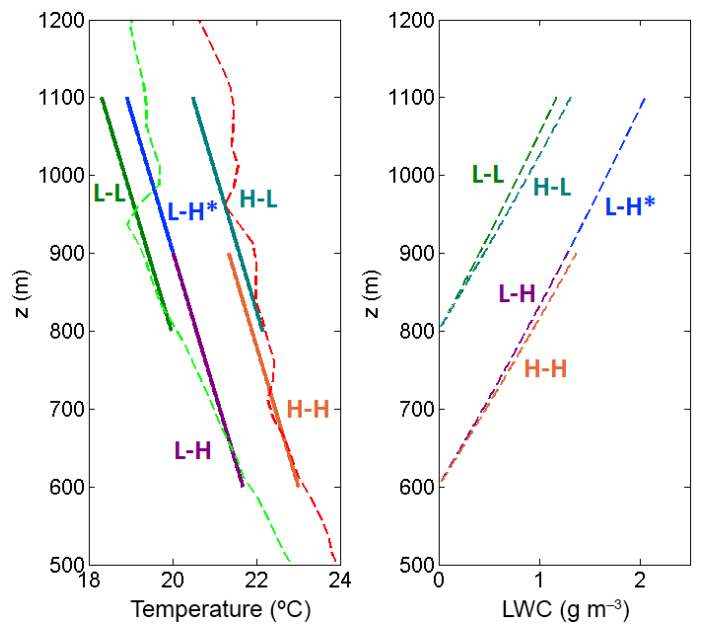

Figure A5. Adiabatic temperature profiles (left) and cloud LWC profiles (right) for the cases described in the text. Numerical values are given in Table A2.

ues $T_{\mathrm{L}}$ and $T_{\mathrm{H}}$ as shown in Fig. A5. For RH, $z_{\mathrm{LCL}}$ is taken as a proxy for $z_{\mathrm{cb}}$; for this idealized experiment, the heights $z_{\mathrm{LCL}, \mathrm{L}}$ and $z_{\mathrm{LCL}, \mathrm{H}}$ are approximated at 800 and $600 \mathrm{~m}$, a dif-

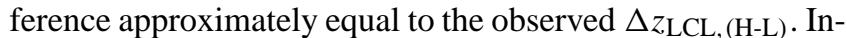
cloud lapse rates are assumed to be constant at $-5.5 \mathrm{~K} \mathrm{~km}^{-1}$.

For a cloud of fixed thickness, lowering the cloud base $z_{\mathrm{cb}}$ along the same temperature profile and raising the cloud base temperature for a fixed $z_{\mathrm{cb}}$ have roughly the same effect on cloud LWP: an increase of 17 and $22 \mathrm{~g} \mathrm{~m}^{-2}$, respectively. Both of these changes are effectively negligible given the much larger magnitude of the observed H-L LWP differences we seek to explain.
Table A2. Adiabatic estimate of cloud liquid water with several different parameters. $\Delta T$ refers to the deviation from the $\mathrm{L}$ profile at $z_{\mathrm{cb}}$ (green line in Fig. A5). The case name refers to the temperature and humidity conditions imposed; i.e., Case $\mathrm{H}-\mathrm{L}$ corresponds to the high temperature, low humidity case. $H^{*}$ represents a cloud base height corresponding to Case $\mathrm{H}$, with the additional condition of cloud top height that of Case L (i.e., thicker clouds).

\begin{tabular}{lrrrrr}
\hline Case & $\Delta T$ & $z_{\mathrm{cb}}$ & $z_{\mathrm{ct}}$ & LWP & $\begin{array}{r}\text { Diff. from } \\
\text { base case }\end{array}$ \\
\hline $\mathrm{L}-\mathrm{L}$ & $+0^{\circ} \mathrm{C}$ & $800 \mathrm{~m}$ & $1100 \mathrm{~m}$ & $178.7 \mathrm{~g} \mathrm{~m}^{-2}$ & $0 \mathrm{~g} \mathrm{~m}^{-2}$ \\
$\mathrm{H}-\mathrm{L}$ & $+2.1^{\circ} \mathrm{C}$ & $800 \mathrm{~m}$ & $1100 \mathrm{~m}$ & $200.3 \mathrm{~g} \mathrm{~m}^{-2}$ & $21.6 \mathrm{~g} \mathrm{~m}^{-2}$ \\
$\mathrm{~L}-\mathrm{H}$ & $+0^{\circ} \mathrm{C}$ & $600 \mathrm{~m}$ & $900 \mathrm{~m}$ & $195.2 \mathrm{~g} \mathrm{~m}^{-2}$ & $16.5 \mathrm{~g} \mathrm{~m}^{-2}$ \\
$\mathrm{H}-\mathrm{H}$ & $+1.3^{\circ} \mathrm{C}$ & $600 \mathrm{~m}$ & $900 \mathrm{~m}$ & $209.1 \mathrm{~g} \mathrm{~m}^{-2}$ & $30.6 \mathrm{~g} \mathrm{~m}^{-2}$ \\
$\mathrm{~L}-H^{*}$ & $+0^{\circ} \mathrm{C}$ & $600 \mathrm{~m}$ & $1100 \mathrm{~m}$ & $529.1 \mathrm{~g} \mathrm{~m}^{-2}$ & $350.4 \mathrm{~g} \mathrm{~m}^{-2}$ \\
\hline
\end{tabular}

Thus, for clouds of similar thickness, we find that the higher temperature or relative humidity alone cannot explain the higher observed cloud water contents of Case H. However, for a lowering of the cloud base while holding cloud top constant (i.e., thicker clouds), the adiabatic LWC is found to increase by $350 \mathrm{~g} \mathrm{~m}^{-2}$. Accounting for average subadiabaticity, this difference is still $\sim 200 \mathrm{~g} \mathrm{~m}^{-2}$.

We additionally note that a physical thickening of the cloud due to higher cloud tops would have a similar effect, although the magnitude is somewhat smaller: for a $500 \mathrm{~m}$ thick cloud with cloud base at $800 \mathrm{~m}$, the LWP would be $484 \mathrm{~g} \mathrm{~m}^{-2}$ for an increase of $306 \mathrm{~g} \mathrm{~m}^{-2}$ over the base case. However, the observations suggest that a lowering of the cloud base is at least a significant contributing factor to the cloud thickening (e.g., Figs. 8, 9, and 10). 

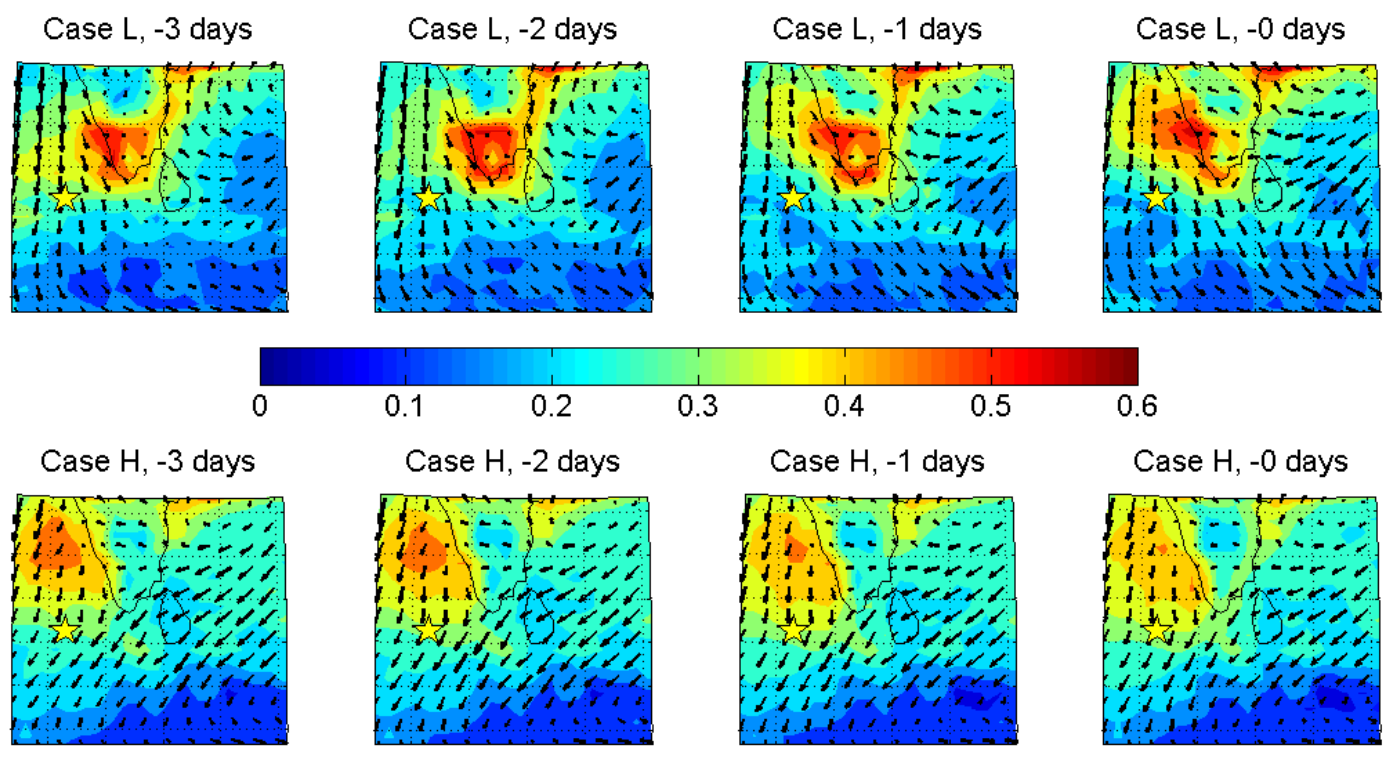

Case $\mathrm{H},-0$ days

.
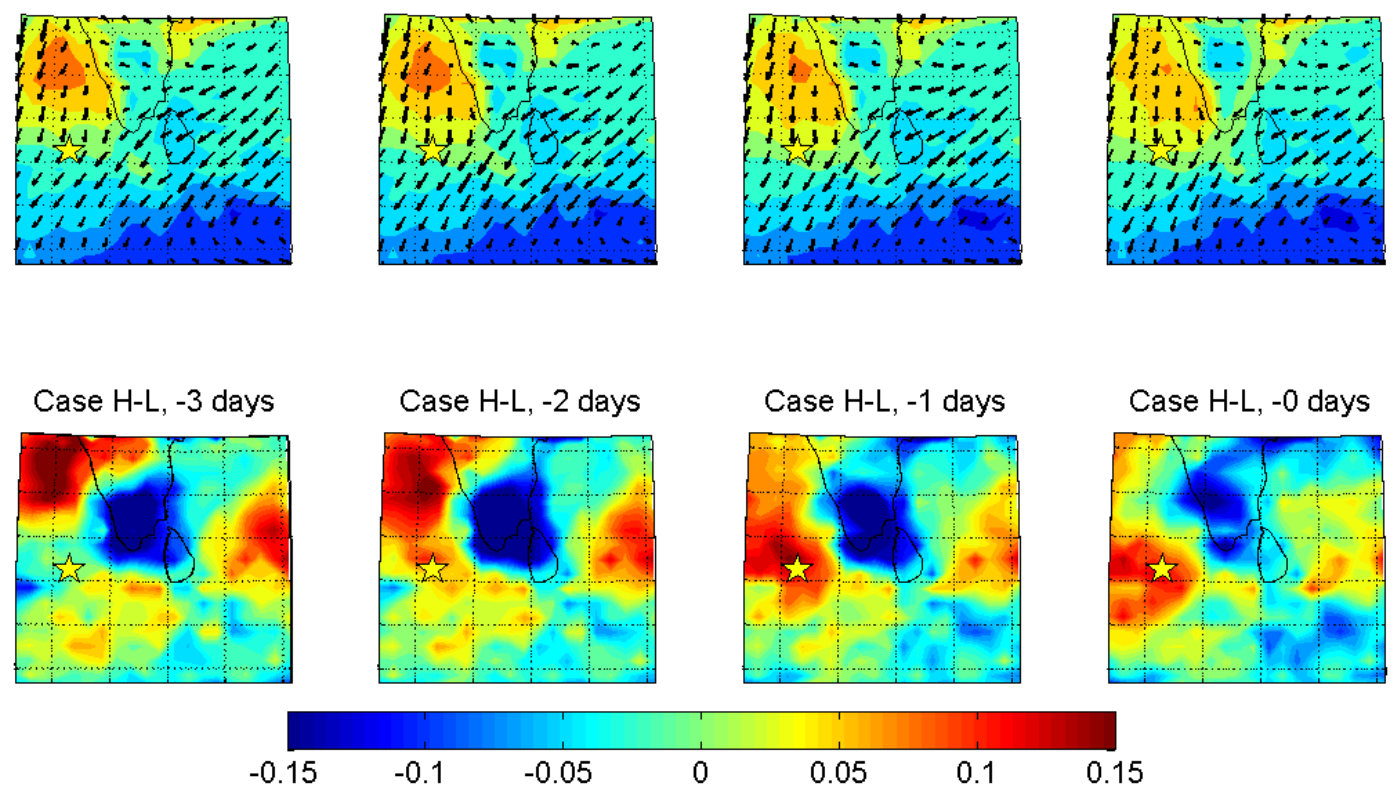

Figure A6. Average daily MODIS AOD for (top row) Case L, (middle row) Case H, and (bottom row) the difference between the two. Note that this includes all Case $\mathrm{L}$ and Case $\mathrm{H}$ days as identified in Table 1, rather than solely the ones on which a UAV was flown. The color scale shown is the same for both Case $\mathrm{L}$ and $\mathrm{Case} \mathrm{H}$, and the location of $\mathrm{MCOH}$ is indicated by the yellow star. From left to right, the columns are 0 , 1, 2, or 3 days prior to a given classification. Note that while Case H corresponds to higher AOD over MCOH, Case L sees higher AOD over the Indian subcontinent. In Case $\mathrm{H}$, the air mass of high aerosol concentration is seen to move south-southeastward to arrive over MCOH. This corresponds to the HYSPLIT and ECMWF low-level trajectories, indicating that upper-level pollution transport is not dominant in these cases. The arrows overlaid on the top two rows indicate the ECMWF average wind fields at $1000 \mathrm{hPa}$, showing similar north-northwesterly flow approaching $\mathrm{MCOH}$ in both cases. With increasing altitude, the wind can be seen to change to a northeasterly direction around the $850 \mathrm{hPa}$ level, although this change occurs lower in altitude for Case $\mathrm{H}(\sim 900 \mathrm{vs} . \sim 800 \mathrm{hPa})$. 

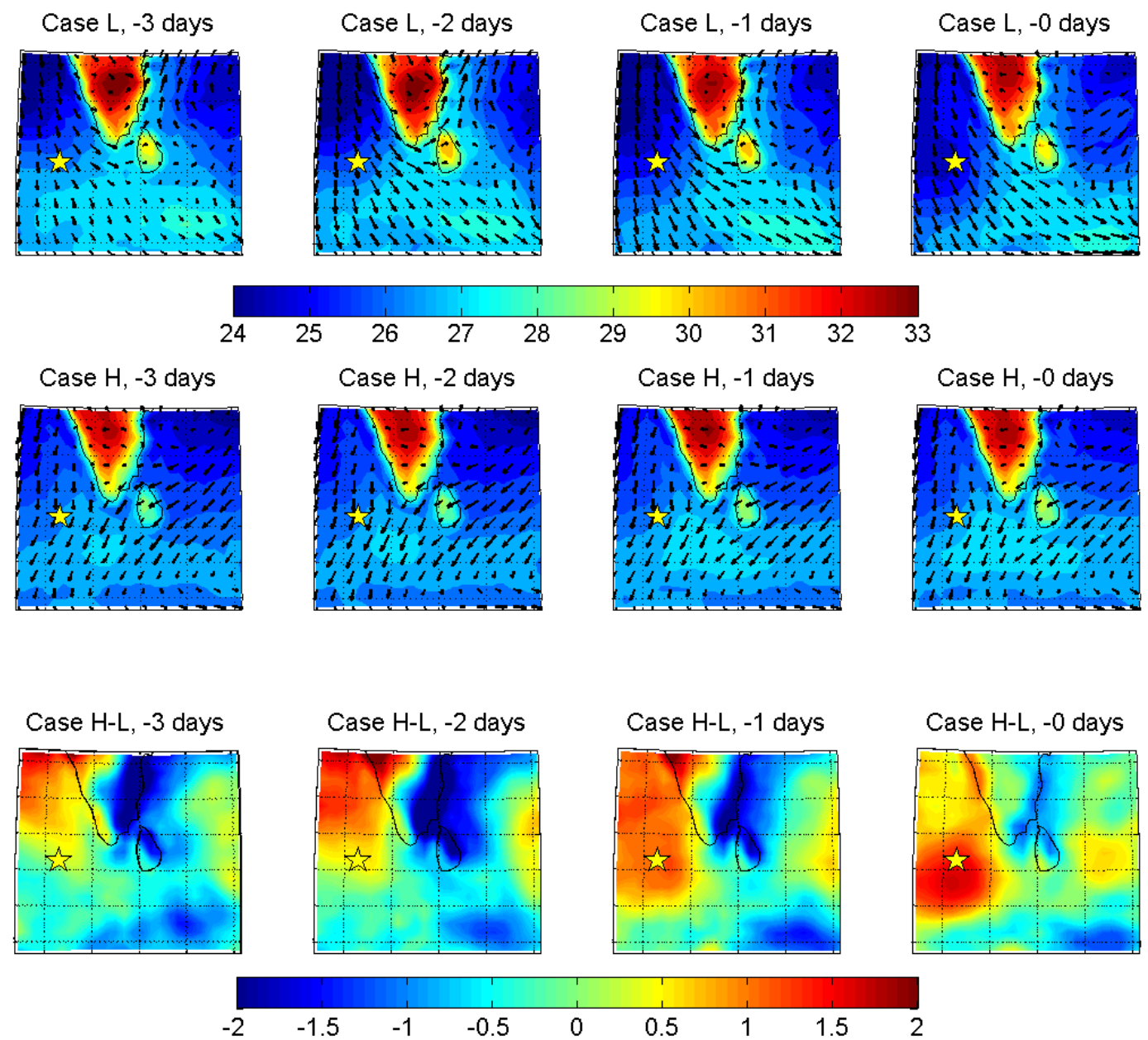

Figure A7. As in Fig. A6 but showing ECMWF $1000 \mathrm{hPa}$ temperature $\left({ }^{\circ} \mathrm{C}\right)$ overlaid with average winds for the preceding 3 days and the day in question - Case L, Case $\mathrm{H}$, or the difference $(\mathrm{H}-\mathrm{L})$. 

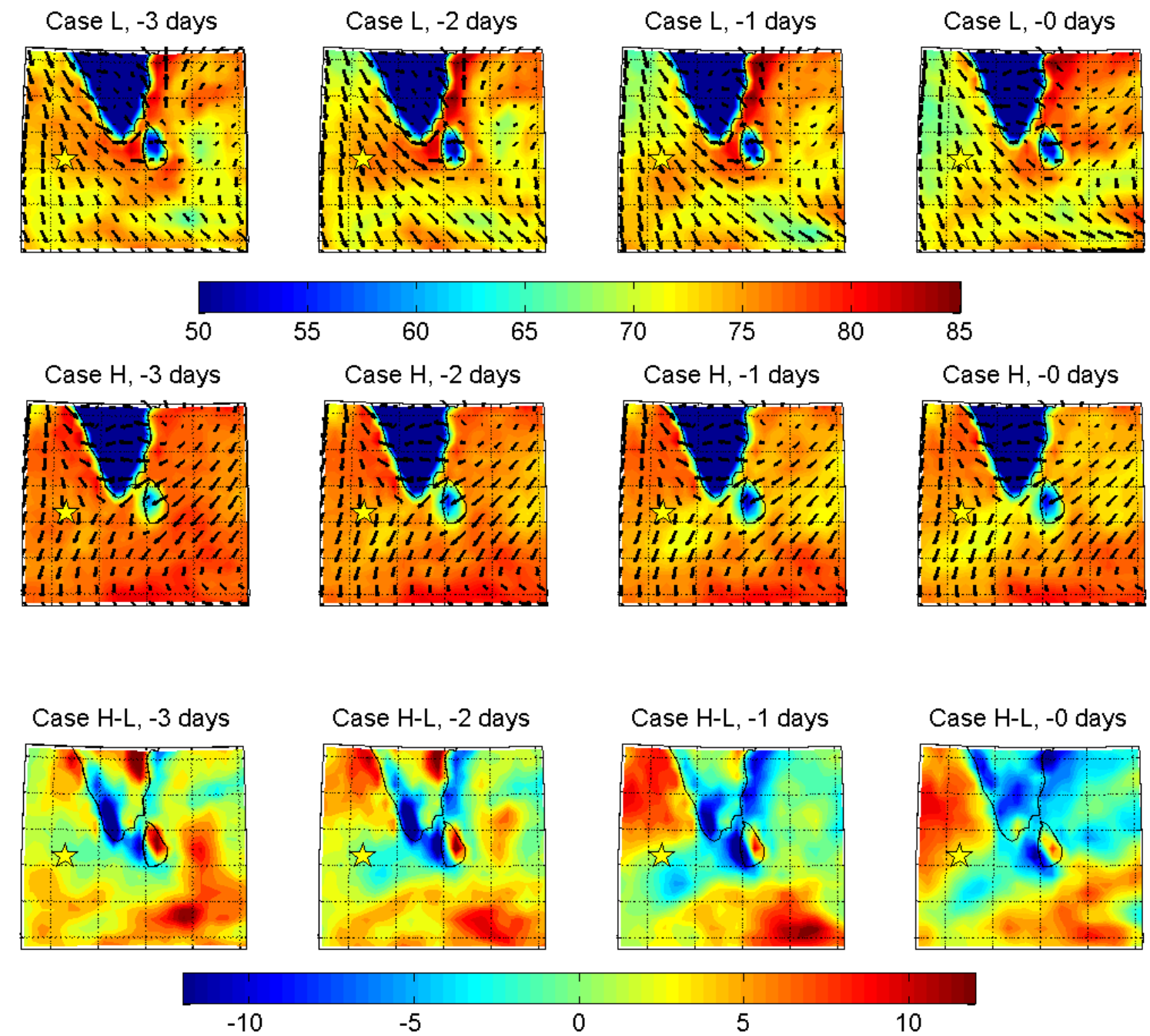

Figure A8. As in Figs. A6 and A7 but showing ECMWF $1000 \mathrm{hPa}$ relative humidity (\%) overlaid with average winds for the preceding 3 days and the day in question - Case L, Case H, or the difference $(\mathrm{H}-\mathrm{L})$. 

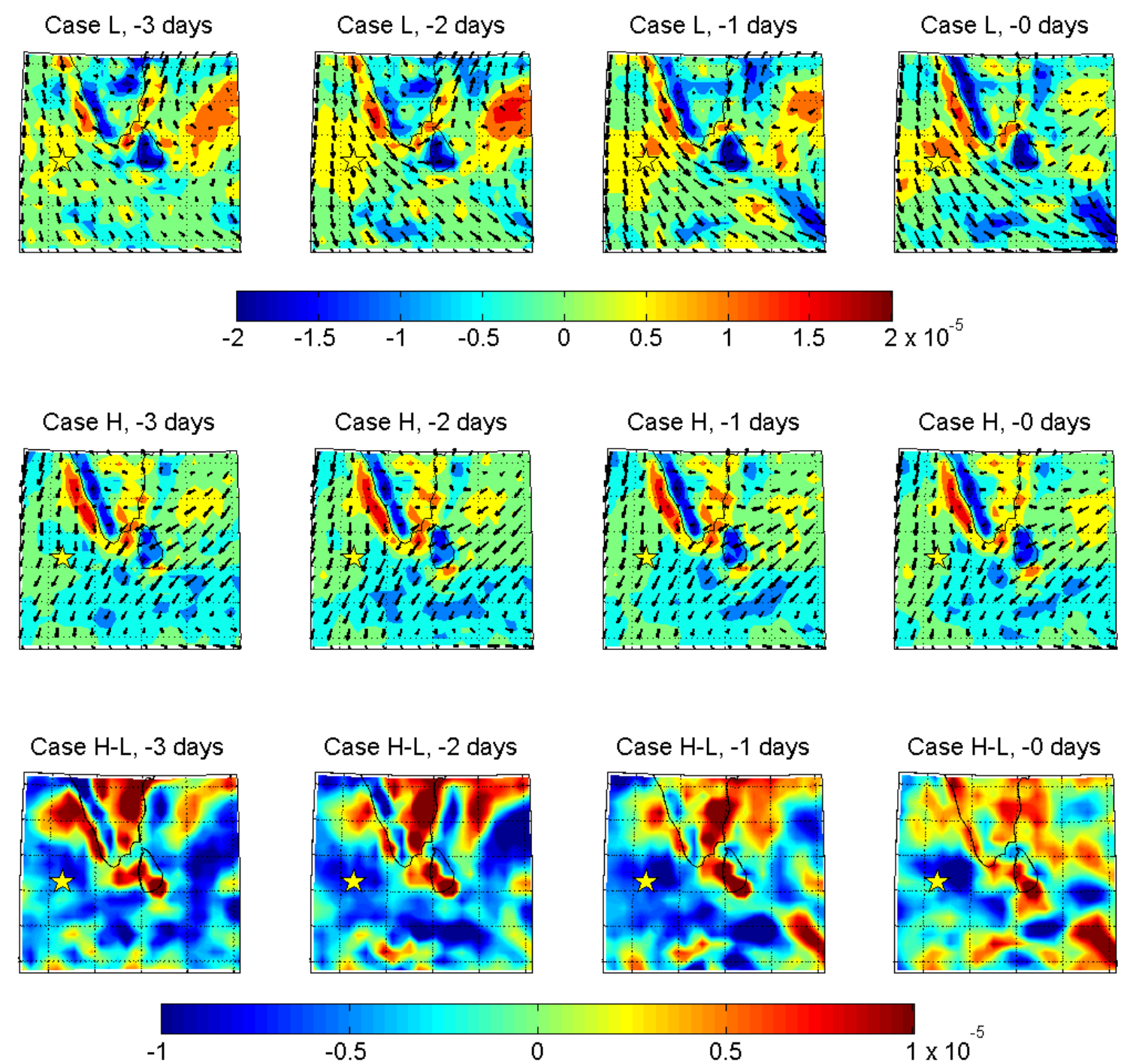

Figure A9. As in Figs. A6 through A8, showing ECMWF $1000 \mathrm{hPa}$ divergence $\left(\mathrm{s}^{-1}\right)$ overlaid with average winds for the preceding 3 days and the day in question - Case L, Case $\mathrm{H}$, or the difference $(\mathrm{H}-\mathrm{L})$. 
Acknowledgements. The CARDEX field campaign was sponsored and funded by the National Science Foundation Grant ATM07-21142 and conducted by the Scripps Institution of Oceanography at the University of California at San Diego in collaboration with the Desert Research Institute, Stockholm University, Argonne National Laboratory, and the Max Planck Institute for Chemistry. Eric M. Wilcox was supported by the Desert Research Institute and NASA grant NNX11AG89G. Veerabhadran Ramanathan is the principal investigator of CARDEX, Eric M. Wilcox is the Co-PI, and H. Nguyen was the field director who conducted the campaign with full support by the government of the Maldives. We also thank the Department of Energy's Atmospheric Radiation Measurement (ARM) Program for use of the microwave radiometer as well as helpful technical advice. Full details of the CARDEX campaign can be found at http: //www-ramanathan.ucsd.edu/files/CARDEX_prop_Jun_20.pdf. This study is Paper no. 3 from the CARDEX campaign.

Edited by: H. Wang

\section{References}

Albrecht, B.: Aerosols, Cloud Microphysics, and Fractional Cloudiness, Science, 245, 1227-1230, doi:10.1126/science.245.4923.1227, 1989.

Augstein, E., Schmidt, H., and Ostapoff, F.: The vertical structure of the atmospheric planetary boundary layer in undisturbed trade winds over the atlantic ocean, Bound.-Lay. Meteorol., 6, 129150, 1974.

Betts, A.: Chapter 4 The Physics and Parameterization of Moist Atmospheric Convection, in: Trade Cumulus: Observations and Modeling, edited by: Smith, R. K., NATO ASI Series C: Vol. 505, Kluwer Academic Publishers, Dordrecht, 99-126, 1997.

Corrigan, C. E., Roberts, G. C., Ramana, M. V., Kim, D., and Ramanathan, V.: Capturing vertical profiles of aerosols and black carbon over the Indian Ocean using autonomous unmanned aerial vehicles, Atmos. Chem. Phys., 8, 737-747, doi:10.5194/acp-8-737-2008, 2008.

Curry, J. A. and Webster, P. J.: Thermodynamics of Atmospheres and Oceans, Academic Press, 1999.

Dee, D. P., Uppala, S. M., Simmons, A. J., Berrisford, P., Poli, P., Kobayashi, S., Andrae, U., Balmaseda, M. A., Balsamo, G., Bauer, P., Bechtold, P., Beljaars, A. C. M., van de Berg, L., Bidlot, J., Bormann, N., Delsol, C., Dragani, R., Fuentes, M., Geer, A. J., Haimberger, L., Healy, S. B., Hersbach, H., Hólm, E. V. and Isaksen, L., Kållberg, P., Köhler, M., Matricardi, M., McNally, A. P., Monge-Sanz, B. M., Morcrette, J.-J., Park, B.-K., Peubey, C., de Rosnay, P., Tavolato, C., Thépaut, J.-N., and Vitart, F.: The ERA-Interim reanalysis: configuration and performance of the data assimilation system, Q. J. Roy. Meteorol. Soc., 137, 553-597, doi:10.1002/qj.828, 2011

Draxler, R. and Rolph, G.: HYSPLIT (hybrid single-particle lagrangian integrated trajectory) model access via NOAA ARL READY website, available at: http://ready.arl.noaa.gov/ HYSPLIT.php (last access: March 2014), NOAA Air Resources Laboratory, College Park, MD, 2013.

French, J., Vali, G., and Kelly, R.: Observations of microphysics pertaining to the development of drizzle in warm, shal- low cumulus clouds, Q. J. Roy. Meteor. Soc., 126, 415-443, doi:10.1256/smsqj.56303, 2000.

Garstang, M. and Betts, A.: Review of Tropical Boundary-Layer and Cumulus Convection - Structure, Parameterization, and Modeling, B. Am. Meteorol. Soc., 55, 1195-1205, 1974.

Heymsfield, A. and McFarquhar, G.: Microphysics of INDOEX clean and polluted trade cumulus clouds, J. Geophys. Res.Atmos., 106, 28653-28673, doi:10.1029/2000JD900776, 2001.

Höpner, F., Bender, F. A.-M., Ekman, A. M. L., Praveen, P. S., Bosch, C., Ogren, J. A., Andersson, A., Gustafsson, Ö., and Ramanathan, V.: Vertical profiles of optical and microphysical particle properties above the northern Indian Ocean during CARDEX 2012, Atmos. Chem. Phys., 16, 1045-1064, doi:10.5194/acp-161045-2016, 2016.

Koch, D. and Del Genio, A. D.: Black carbon semi-direct effects on cloud cover: review and synthesis, Atmos. Chem. Phys., 10, 7685-7696, doi:10.5194/acp-10-7685-2010, 2010.

LaMontagne, R. and Telford, J.: Cloud Top Mixing in Small Cumuli, J. Atmos. Sci. 40, 2148-2156, 1983.

Lawrence, M: The relationship between relative humidity and the dewpoint temperature in moist air - A simple conversion and applications, B. Am. Meteorol. Soc. 86, 225-233, doi:10.1175/BAMS-86-2-225, 2005.

Lawrence, M. G. and Lelieveld, J.: Atmospheric pollutant outflow from southern Asia: a review, Atmos. Chem. Phys., 10, 1101711096, doi:10.5194/acp-10-11017-2010, 2010.

MacPherson, J. and Isaac, G.: Turbulent Characteristics of Some Canadian Cumulus Clouds, J. Appl. Meteorol. 16, 81-90, 1977.

Malkus, J. S.: Marine meteorology: On the structure of tradewind air below cloud, Technical Report no. 40: Unpublished Manuscript 56-52, Woods Hole Oceanographic Institution, doi:10.1575/1912/5433, 1956.

Malkus, J. S.: Marine meteorology: On the structure of the trade wind moist layer, Technical Report no. 42: Unpublished Manuscript 57-59, Woods Hole Oceanographic Institution, doi:10.1575/1912/5443, 1957.

Mauger, G. S. and Norris, J. R.: Meteorological bias in satellite estimates of aerosol-cloud relationships, Geophys. Res. Lett., 34, L16824, doi:10.1029/2007GL029952, 2007.

Mauger, G. S. and Norris, J. R.: Assessing the Impact of Meteorological History on Subtropical Cloud Fraction, J. Climate, 23, 2926-2940, doi:10.1175/2010JCLI3272.1, 2010.

Morris, V. R.: Microwave Radiometer Handbook. Atmospheric Radiation Measurement Climate Research Facility, US Department of Energy, 2006.

Ramana, M. V. and Ramanathan, V.: Abrupt transition from natural to anthropogenic aerosol radiative forcing: Observations at the ABC-Maldives Climate Observatory, J. Geophys. Res.-Atmos., 111, D20207, doi:10.1029/2006JD007063, 2006.

Ramana, M. V., Ramanathan, V., Kim, D., Roberts, G. C., and Corrigan, C. E.: Albedo, atmospheric solar absorption and heating rate measurements with stacked UAVs, Q. J. Roy. Meteor. Soc., 133, 1913-1931, doi:10.1002/qj.172, 2007.

Ramanathan, V. and Carmichael, G.: Global and regional climate changes due to black carbon, Nat. Geosci., 1, 221-227, doi:10.1038/ngeo156, 2008.

Ramanathan, V., Crutzen, P., Lelieveld, J., Mitra, A., Althausen, D., Anderson, J., Andreae, M., Cantrell, W., Cass, G., Chung, C., Clarke, A., Coakley, J., Collins, W., Conant, W., Dulac, F., 
Heintzenberg, J., Heymsfield, A., Holben, B., Howell, S., Hudson, J., Jayaraman, A., Kiehl, J., Krishnamurti, T., Lubin, D., McFarquhar, G., Novakov, T., Ogren, J., Podgorny, I., Prather, K., Priestley, K., Prospero, J., Quinn, P., Rajeev, K., Rasch, P., Rupert, S., Sadourny, R., Satheesh, S., Shaw, G., Sheridan, P., and Valero, F.: Indian Ocean Experiment: An integrated analysis of the climate forcing and effects of the great Indo-Asian haze, J. Geophys. Res.-Atmos., 106, 28371-28398, doi:10.1029/2001JD900133, 2001.

Ramanathan, V., Ramana, M. V., Roberts, G., Kim, D., Corrigan, C., Chung, C., and Winker, D.: Warming trends in Asia amplified by brown cloud solar absorption, Nature, 448, 575-578, doi:10.1038/nature06019, 2007.

Roberts, G. C., Ramana, M. V., Corrigan, C., Kim, D., and Ramanathan, V.: Simultaneous observations of aerosolcloud-albedo interactions with three stacked unmanned aerial vehicles, P. Natl. Acad. Sci. USA, 105, 7370-7375, doi:10.1073/pnas.0710308105, 2008.

Rodts, S., Duynkerke, P., and Jonker, H.: Size distributions and dynamical properties of shallow cumulus clouds from aircraft observations and satellite data, J. Atmos. Sci., 60, 1895-1912, 2003.

Simpson, J. and Dennis, A. S.: Cumulus clouds and their modification, NOAA Technical Memorandum ERL OD-14, National Oceanic and Atmospheric Administration, 1972.
Stanhill, G. and Cohen, S.: Global dimming: a review of the evidence for a widespread and significant reduction in global radiation with discussion of its probable causes and possible agricultural consequences, Agr. Forest Meteorol., 107, 255-278, doi:10.1016/S0168-1923(00)00241-0, 2001.

Stevens, B. and Feingold, G.: Untangling aerosol effects on clouds and precipitation in a buffered system, Nature, 461, 607-613, doi:10.1038/nature08281, 2009.

Thomas, R. M., Praveen, P., Wilcox, E. M., Pistone, K., Bender, F., and Ramanathan, V.: First uav measurements of entrainment layer fluxes with coupled cloud property measurements, American Geophysical Union, 2012.

Twomey, S.: Pollution and Planetary Albedo, Atmos. Environ. 8, 1251-1256, doi:10.1016/0004-6981(74)90004-3, 1974.

Warner, J.: The Water Content of Cumuliform Cloud, Tellus 7, 449_ 457, 1955.

Wilcox, E. M., Thomas, R. M., Praveen, P., Pistone, K., Bender, F., Feng, Y., and Ramanathan, V.: Shallow cumulus clouds embedded in a deep regional haze: Results from Indian Ocean CARDEX experiment, American Meteorological Society, 2014.

Wild, M: Global dimming and brightening: A review, J. Geophys. Res.-Atmos., 114, D00D16, doi:10.1029/2008JD011470, 2009. 